\title{
An experimental study on the acoustic characteristics of outdoor spaces surrounded by multi-residential buildings
}

\author{
Hong-Seok Yang ${ }^{\mathrm{a}}$, Jian Kang ${ }^{\mathrm{b}}$, Myung-Jun Kim ${ }^{\mathrm{c}, ~ *}$ \\ ${ }^{a}$ Land and Housing Institute, Korea Land and Housing Corporation, Daejeon 34047, South Korea \\ ${ }^{\mathrm{b}}$ School of Architecture, University of Sheffield, Sheffield S10 2TN, United Kingdom \\ ${ }^{c}$ School of Architecture, University of Seoul, Seoul 02504, South Korea \\ * Corresponding author
}

\begin{abstract}
A comfortable sound environment in the outdoor spaces of apartment complexes contributes to the improvement of the overall environmental quality. It is expected that the characteristics of room acoustical parameters and sound pressure level (SPL) attenuation of outdoor spaces surrounded by multi-residential buildings depends on many design factors such as the openness, volume, and building layouts, etc. The aim of this study is to clarify the influential factors determining room acoustical parameters and SPL attenuation in outdoor spaces that are surrounded by buildings with complicated topographical conditions. A series of measurements was carried out for 15 outdoor spaces in 6 apartment complexes with different building layouts. The 15 outdoor spaces were categorized into 4 types of building layouts: linear-shaped, parallelshaped, U-shaped, and square-shaped. The result showed that reverberation time (RT) at $500 \mathrm{~Hz}$ and $1000 \mathrm{~Hz}$ is relatively long, over $4 \mathrm{sec}$, with uneven RT distribution showing a non-diffuse field. With increasing source to receiver distance, the RT and early decay time (EDT) increased logarithmically. On the other hand, the Definition $\left(\mathrm{D}_{50}\right)$ and rapid speech transmission index (RASTI) decreased with increasing source to receiver distances. The result for the SPL attenuation measured at a $20 \mathrm{~m}$ source to receiver distance in 10 outdoor spaces showed a 17.7 $\mathrm{dB}$ difference between the 10 spaces due to the influence of building geometry. An empirical method considering the openness, size-related parameters, and room constant is also suggested to predict the approximate RT and SPL attenuation in the outdoor spaces.
\end{abstract}

Key word: Sound attenuation, Reverberation, Outdoor space, Multi-residential building, Noise 2017 Applied Acoustics

Date Received: 30 October 2016 Date Accepted: 31 May 2017

Publish online: 13 June 2017 


\section{INTRODUCTION}

High-rise apartment buildings have been universally built for residential purposes due to the increasing population density in urbanized cities. An apartment complex consists of several apartment buildings in a limited area of land with various types of building layouts and blocks of buildings. Outdoor spaces in an apartment complex are planned by considering many architectural, environmental, and social factors such as car parking, natural lighting, and outdoor activities [1]. Recently, the importance of the outdoor spaces for leisure and rest has also been given particular attention, especially with the increase of the available land for such uses due to underground car parking. Therefore, designing environments that have a comfortable sound environment in outdoor spaces can contribute to improving the living quality of residents.

Two approaches can be considered when designing spaces for effective noise reduction in outdoor urban environments. The first approach is to reduce background noise from external noise sources such as road traffic, and the second approach is to reduce background noise from internal noise sources such as human voices in the outdoor spaces. The majority of noise abatement schemes have mainly adopted the first approach related to reducing background noise from the external noise sources such as traffic noise by means of noise barriers as well as by the building layout such as introducing courtyards [2-7]. This conventional approach is based on the concept that a lower background noise could help residents to feel less stressed.

Although reducing background noise in outdoor spaces is an effective noise abatement approach, it causes a relatively high signal to noise ratio $(\mathrm{S} / \mathrm{N})$ for the internal noise sources such as human conversation, pedestrian noise, and passing traffic. Therefore, it is also important to control the sound field of the outdoor space by means of acoustic materials with a high absorption coefficient such as green walls and soil which can reduce the increased sound pressure level (SPL) and reverberation time (RT) due to multiple reflections between building façades [8-11].

Numerous studies have been carried out to characterize sound fields with acoustic descriptors including RT and SPL distribution. The results showed that RT and SPL distribution are useful parameters to predict transient and steady-state sound propagation in urban spaces that are influenced by complicated acoustic phenomena such as multiple reflections, diffraction, and diffusion due to surrounding buildings and obstacles. Thus, various prediction models for RT and SPL distribution have been developed for microscale urban environments to understand the effect of boundary conditions and width-to-height ratio in sound propagation [12-15]. The results from these prediction models suggest that with diffusely reflecting boundaries, the RT is shorter than that with geometrically reflecting boundaries. It was also predicted that the RT in street canyons increases with increasing source to receiver distances for both diffusely and geometrically reflecting boundaries.

Several studies have also involved site and scale model measurements to examine sound propagation characteristics in urban spaces [16-21]. Ismail and Oldham [22] investigated the role of sound reflection from building façades with irregular surfaces using physical scale models. 
The result suggested that the scattering coefficient is about $0.09-0.13$ for urban façades in Europe. Although the scattering coefficient is small, the diffuse reflection mechanism is dominant at higher orders of reflections due to the effect of multiple reflections. Thomas et al. [23] carried out a series of measurements in 99 streets to examine the influence of geometrical parameters such as street width, average height, and façade roughness in SPL distribution by analyzing the reflection ratio, defined as the reverberant to direct sound energy ratio. The result showed that the reflection ratio strongly correlates with the street width. A model was also suggested to predict SPL according to the influence of changes in the street width and average building height in street canyons.

In comparison with street canyons and squares, the acoustic quality in outdoor spaces of residential buildings could be more important because residents require a high level of comfortable sound environments for leisure and rest in outdoor spaces and in living rooms that face outdoor spaces. This is especially important during summer when residents open their windows, because sound energy containing multiple reflections transmits through the indoor spaces of high floors [24]. Thus, it is important that architects understand how architectural design can affect the RT and SPL attenuation in outdoor spaces.

The purpose of this study is therefore to investigate the acoustic characteristics of outdoor spaces surrounded by multi-residential buildings by analyzing data measured in 15 outdoor spaces of 6 apartment complexes with different building layouts. The 15 outdoor spaces were categorized into 4 types of building layouts: linear-shaped, parallel-shaped, U-shaped, and square-shaped. Some of the measurement data (4 of 15 outdoor spaces) from the preliminary work was used for the parametric study [24]. Based on the site measurements, the RT, early decay time (EDT), and SPL attenuation were analyzed according to the source to receiver distances. The characteristics of room acoustical parameters were also analyzed using Definition $\left(\mathrm{D}_{50}\right)$ and the rapid speech transmission index (RASTI), both of which are related to speech intelligibility. An empirical model using AutoCAD to predict RT and SPL attenuation is also suggested in this study.

\section{METHODOLOGY}

\subsection{Description of the studied sites}

In this study, a series of field measurements was conducted to investigate the characteristics of sound propagation in 15 outdoor spaces of 6 apartment complexes in Korea. The apartment complexes were selected by taking into account the types of building layouts and building blocks. Figure 1 shows the bird's-eye views for each apartment complex and Figure 2 shows the photographs for each site. Table 1 describes the site and measurement conditions for each apartment complex.

As shown in Figures 1 and 2, each apartment complex has a different building layout, block, size, and height. On the other hand, most of the building façades have acoustically reflective 


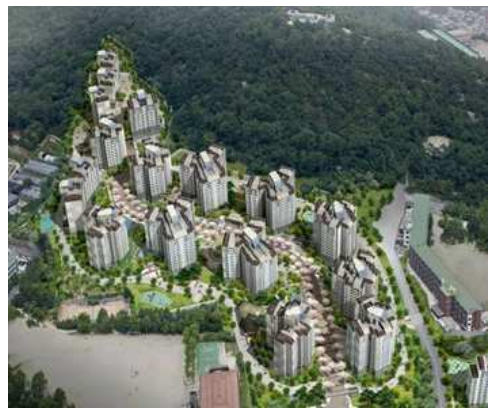

(a) Site 1 (Jeon-Nong)

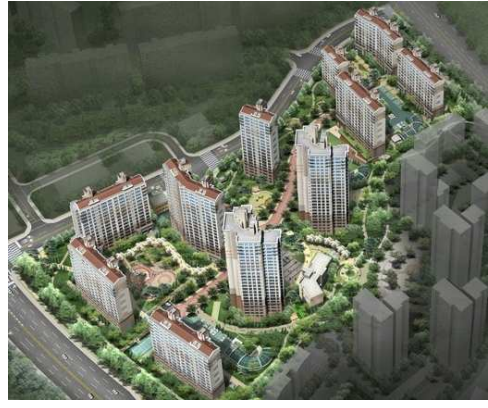

(d) Site 4 (Pa-Ju)

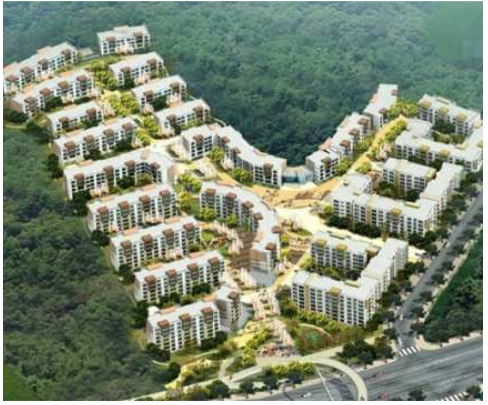

(b) Site 2 (Shin-Jung $2^{\text {nd }}$ )

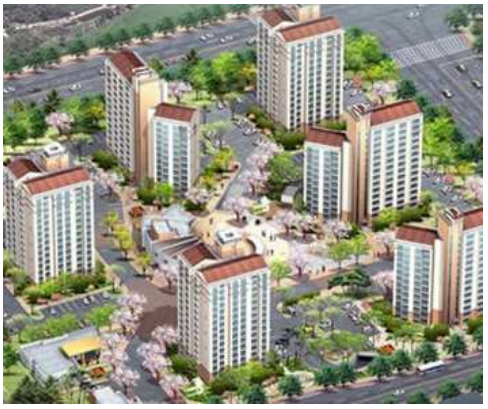

(e) Site 5 (Jeung-Pyung)

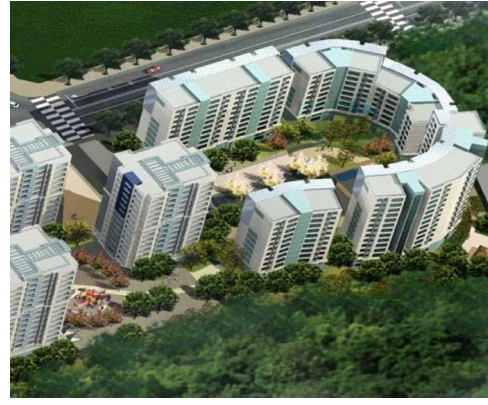

(c) Site 3 (Shin-Jung $5^{\text {th }}$ )

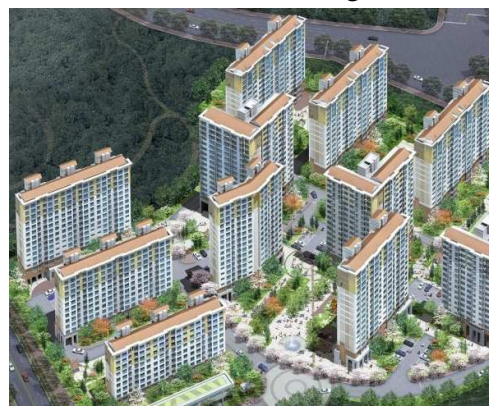

(f) Site 6 (Chon-Wang)

Fig. 1 Bird's-eye views of each apartment complex

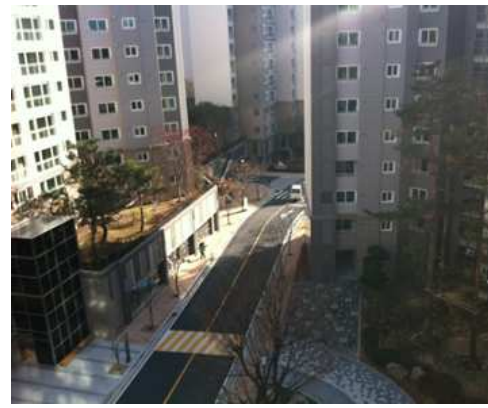

(a) Site 1 (Jeon-Nong)

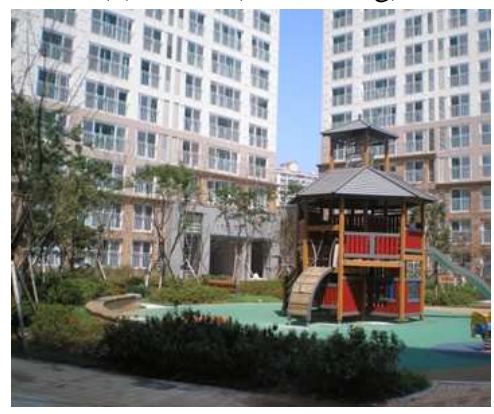

(d) Site 4 (Pa-Ju)

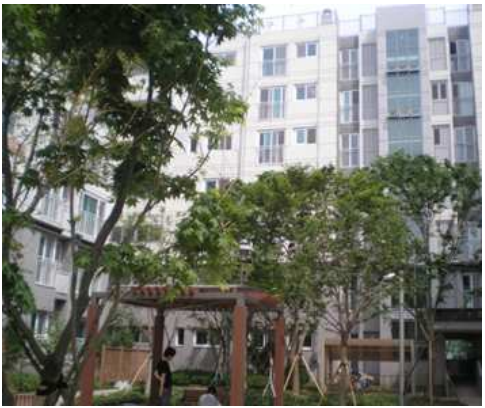

(b) Site 2 (Shin-Jung $2^{\text {nd }}$ )

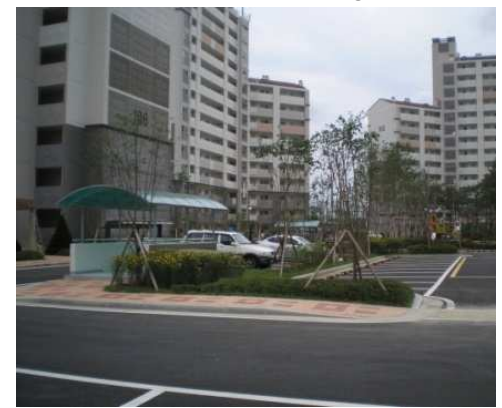

(e) Site 5 (Jeung-Pyung)

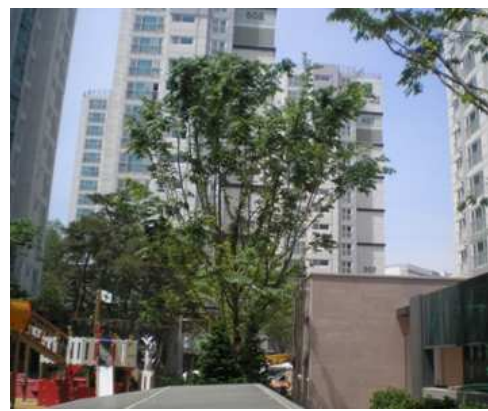

(c) Site 3 (Shin-Jung $5^{\text {th }}$ )

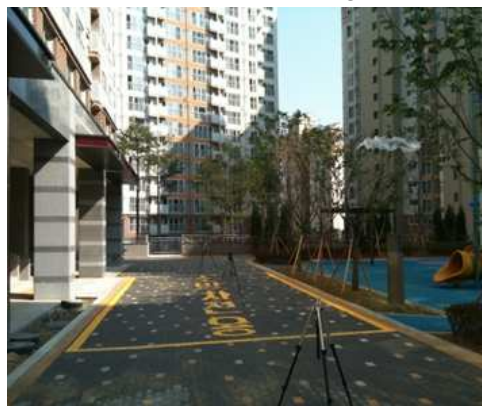

(f) Site 6 (Chon-Wang)

Fig. 2 Photographs of each apartment complex

surfaces with concrete walls and window balconies, which can result in relatively long RT and increased SPL due to strong specula reflections in comparison with a semi-free field. 
Table 1 Site and measurement conditions for each apartment complex

\begin{tabular}{|c|c|c|c|c|c|c|}
\hline & Site 1 & Site 2 & Site 3 & Site 4 & Site 5 & Site 6 \\
\hline Name & Jeon-Nong & $\begin{array}{c}\text { Shin-Jung } \\
2^{\text {nd }}\end{array}$ & Shin-Jung 5 & Pa-Ju & Jeung-Pyung & Chon-Wang \\
\hline $\begin{array}{c}\text { No. of } \\
\text { buildings }\end{array}$ & 15 & 20 & 8 & 11 & 6 & 13 \\
\hline No. of flats & 867 & 471 & 238 & 648 & 504 & 1044 \\
\hline No. of floors & $9 \sim 15$ & $3 \sim 7$ & $9 \sim 15$ & $12 \sim 25$ & $10 \sim 15$ & $9 \sim 18$ \\
\hline $\begin{array}{c}\text { Temp. } \\
\left({ }^{\circ} \mathrm{C}\right)\end{array}$ & 11.1 & 21.5 & 21.5 & 24.3 & 26.4 & 21.2 \\
\hline $\begin{array}{c}\text { Humidity } \\
(\%)\end{array}$ & 56.5 & 39.5 & 39.5 & 60.1 & 57.5 & 57.5 \\
\hline $\begin{array}{c}\text { Wind speed } \\
(\mathrm{m} / \mathrm{s})\end{array}$ & $<3.3$ & $<2.0$ & $<2.0$ & $<2.1$ & $<1.5$ & $<2.1$ \\
\hline
\end{tabular}

In Figure 3, the 15 measurement zones in the apartment complexes are shown. The building layouts surrounding the outdoor spaces are categorized into 4 types: linear-shaped (i.e. -), parallel-shaped (i.e. =), U-shaped (i.e. U), and rectangular-shaped (i.e. $\square$ ). The building blocks also have 4 different types which can be categorized as linear, L, U, and Y types.

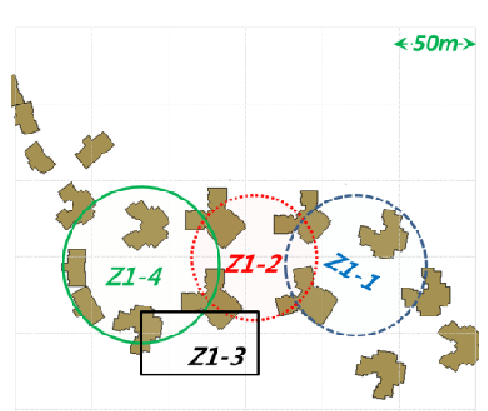

(a) Site 1 (Jeon-Nong)

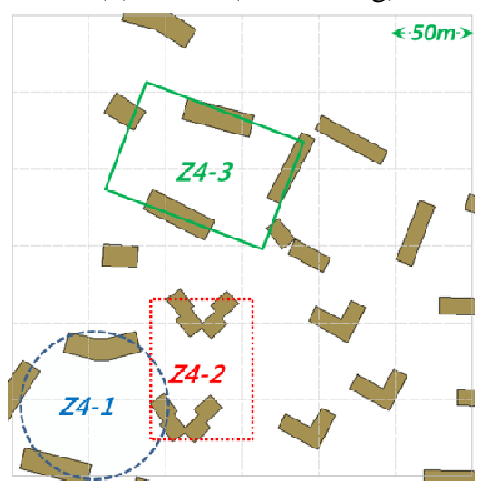

(d) Site 4 (Pa-Ju)

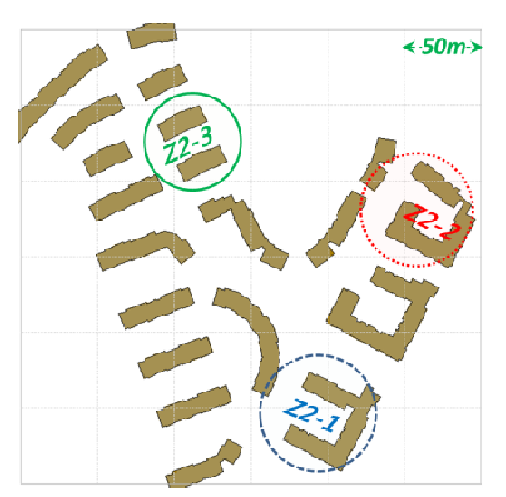

(b) Site 2 (Shin-Jung $2^{\text {nd }}$ )

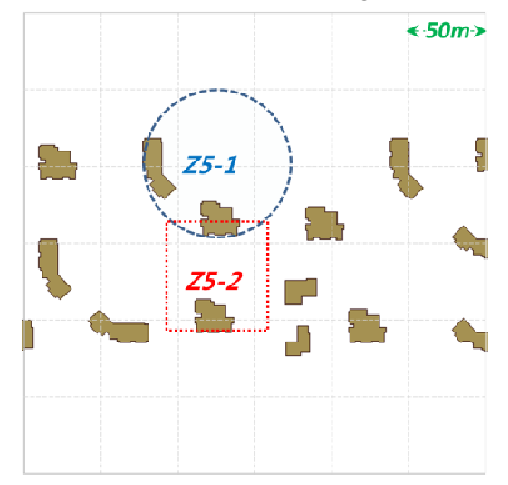

(e) Site 5 (Jeung-Pyung)

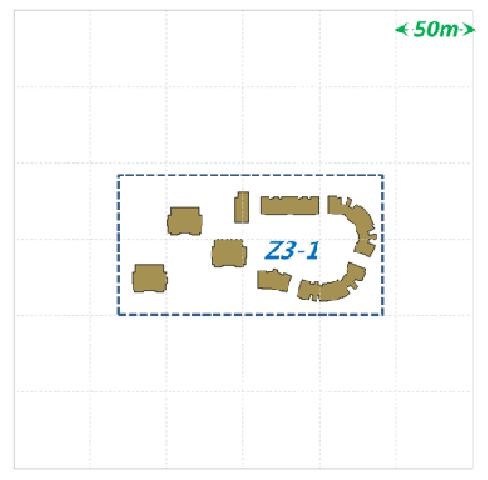

(c) Site 3 (Shin-Jung $5^{\text {th }}$ )

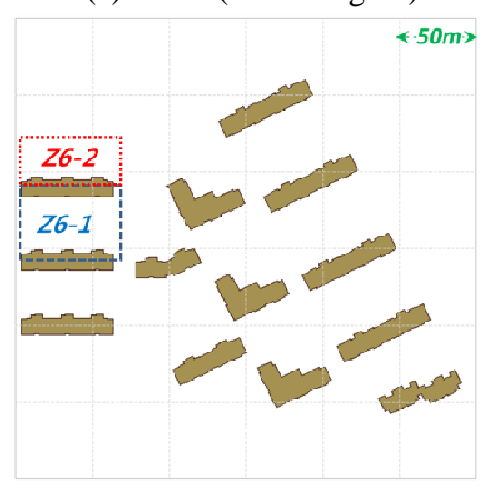

(f) Site 6 (Chon-Wang)

Fig. 3 Ground plan and measurement zones for each apartment complex 


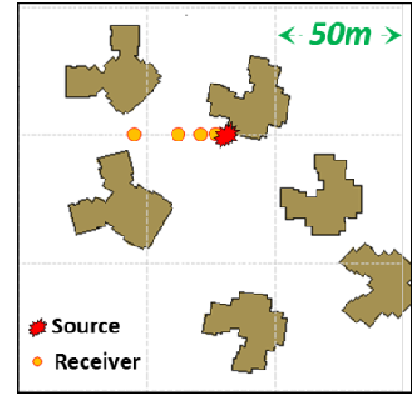

(a) Z1-1 (U type)

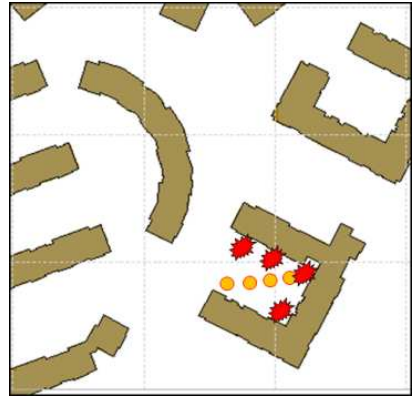

(e) Z2-1 (U type)

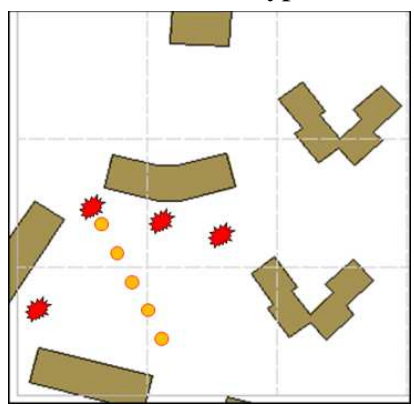

(i) Z4-1 (U type)

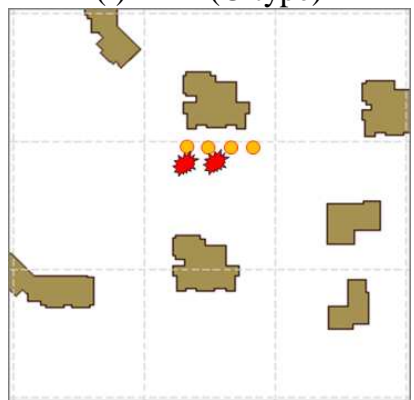

(m) Z5-2 (= type)

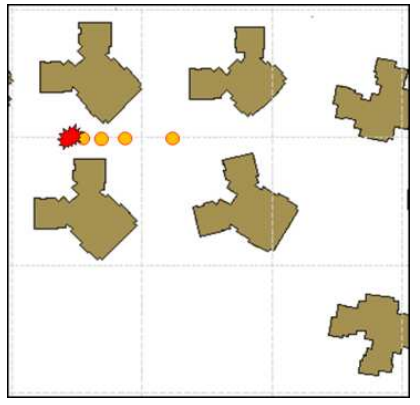

(b) Z1-2 ( $\square$ type)

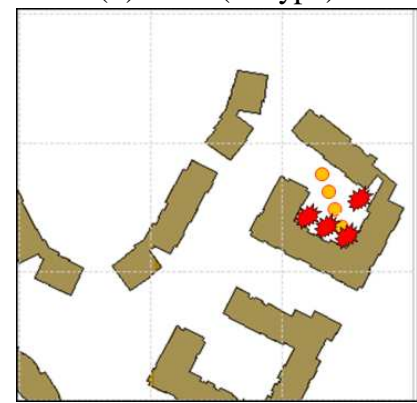

(f) Z2-2 (U type)

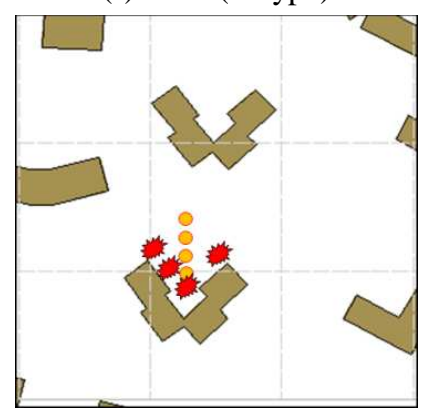

(j) Z4-2 (= type)

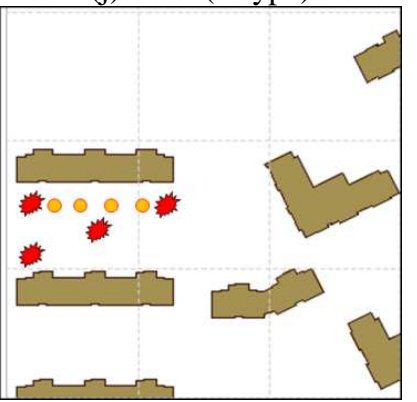

(n) Z6-1 (= type)

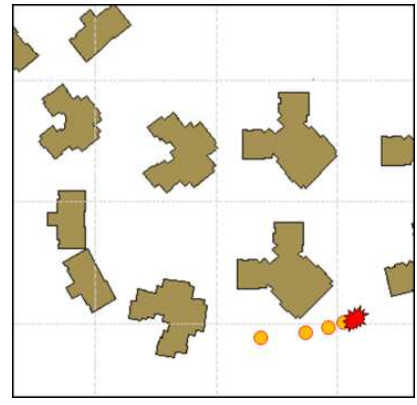

(c) Z1-3 (- type)

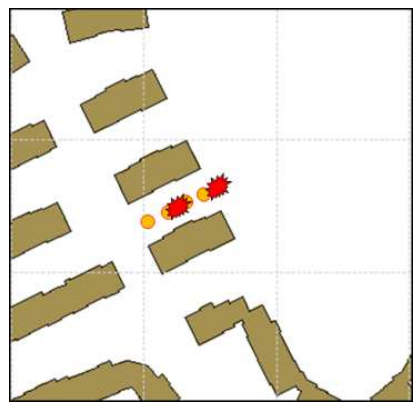

(g) Z2-3 (= type)

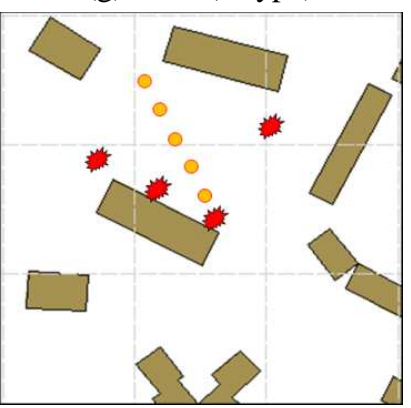

(k) Z4-3 (= type)

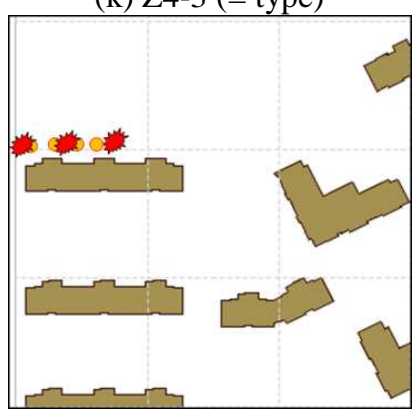

(o) Z6-2 (- type)

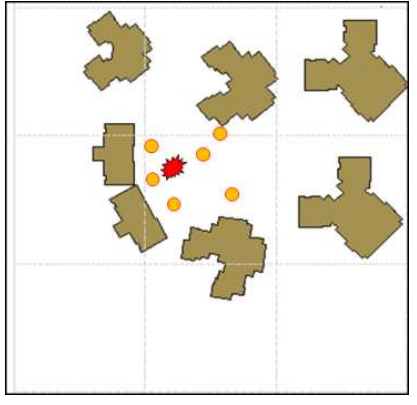

(d) Z1-4 ( $\square$ type)

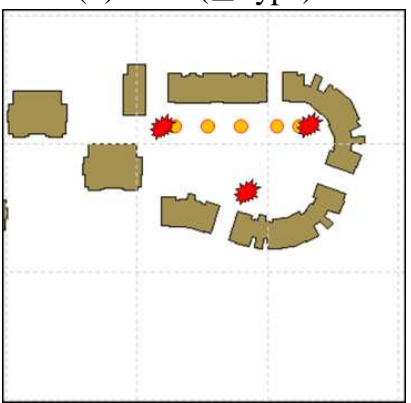

(h) Z3-1 ( $\square$ type)

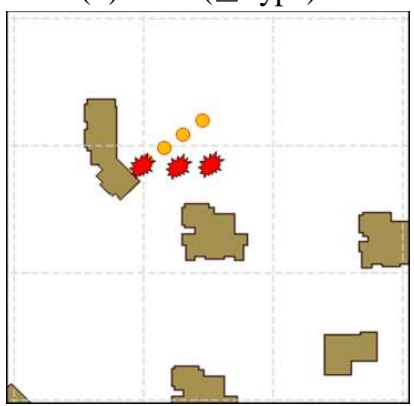

(1) Z5-1(- type)

Fig. 4 Locations of source to receiver points in the 15 zones

The number and location of the source and receiver points at each measurement zone is described in Table 2, with a total of 209 points used to measure impulse responses. While the receiver points (microphone) were fixed in an outdoor space, the locations of the source points (pistol) were changed in order to analyze the RT distribution in an outdoor space. A measurement of SPL attenuation was also carried out using a speaker for the source to receiver points along a line of sight in 11 zones. The source to receiver distance for each measurement Applied Acoustics, Volume 127,2017, Pages 147-159 
Table 2 Description on source to receiver points and measurement parameters at each measurement zone

\begin{tabular}{|c|c|c|c|c|c|c|c|}
\hline & \multirow[t]{2}{*}{$\begin{array}{l}\text { Name of } \\
\text { zone }\end{array}$} & \multirow[t]{2}{*}{$\begin{array}{l}\text { No. of } \\
\text { sources }\end{array}$} & \multirow[t]{2}{*}{$\begin{array}{l}\text { No. of } \\
\text { receiver }\end{array}$} & \multirow[t]{2}{*}{$\begin{array}{l}\text { Source-receiver } \\
\text { distance }(\mathrm{m})\end{array}$} & \multicolumn{2}{|c|}{$\begin{array}{c}\text { Measurement } \\
\text { parameter }\end{array}$} & \multirow{2}{*}{$\begin{array}{l}\text { Type of } \\
\text { building } \\
\text { layout }\end{array}$} \\
\hline & & & & & $\begin{array}{l}\text { Impulse } \\
\text { response }\end{array}$ & $\begin{array}{c}\text { SPL } \\
\text { attenuation }\end{array}$ & \\
\hline \multirow[t]{4}{*}{ Site 1} & $\mathrm{Z} 1-1$ & 1 & 5 & $1,5,10,20,40$ & $\mathrm{O}$ & $\mathrm{O}$ & $\mathrm{U}$ \\
\hline & $\mathrm{Z} 1-2$ & 1 & 5 & $1,5,10,20,40$ & $\mathrm{O}$ & $\mathrm{O}$ & $\square$ \\
\hline & Z1-3 & 1 & 5 & $1,5,10,20,40$ & $\mathrm{O}$ & $\mathrm{O}$ & - \\
\hline & Z1-4 & 1 & 6 & $9,10,12,13,20,21$ & $\mathrm{O}$ & $X$ & $\square$ \\
\hline \multirow[t]{3}{*}{ Site 2} & Z2-1 & 4 & 5 & $1,7,14,21,28$ & $\mathrm{O}$ & $\mathrm{O}$ & $\mathrm{U}$ \\
\hline & $\mathrm{Z} 2-2$ & 4 & 5 & $1,7,14,21,28$ & $\mathrm{O}$ & $\mathrm{X}$ & $\mathrm{U}$ \\
\hline & $\mathrm{Z} 2-3$ & 2 & 5 & $1,7,14,21,28$ & $\mathrm{O}$ & $\mathrm{O}$ & $=$ \\
\hline Site 3 & Z3-1 & 3 & 6 & $1,5,15,25,35,45$ & $\mathrm{O}$ & $\mathrm{X}$ & $\square$ \\
\hline \multirow[t]{3}{*}{ Site 4} & $\mathrm{Z} 4-1$ & 4 & 6 & $1,10,20,30,40,50$ & $\mathrm{O}$ & $\mathrm{O}$ & $\mathrm{U}$ \\
\hline & Z4-2 & 4 & 5 & $1,5,10,15,20$ & $\mathrm{O}$ & $\mathrm{O}$ & $=$ \\
\hline & Z4-3 & 4 & 6 & $1,10,20,30,40,50$ & $\mathrm{O}$ & $\mathrm{O}$ & $=$ \\
\hline \multirow[t]{2}{*}{ Site 5} & $\mathrm{Z5-1}$ & 3 & 4 & $1,7,14,21,28$ & $\mathrm{O}$ & $\mathrm{O}$ & - \\
\hline & $\mathrm{Z} 5-2$ & 2 & 4 & $1,7,14,21$ & $\mathrm{O}$ & $\mathrm{X}$ & $=$ \\
\hline \multirow[t]{2}{*}{ Site 6} & Z6-1 & 4 & 5 & $1,10,20,30,40$ & $\mathrm{O}$ & $\mathrm{O}$ & $=$ \\
\hline & Z6-2 & 3 & 4 & $1,8,16,24$ & $\mathrm{O}$ & $\mathrm{O}$ & - \\
\hline
\end{tabular}

zone was determined by considering the size of the outdoor spaces. Figure 4 illustrates the locations of source to receiver points in the 15 zones.

\subsection{Measurement method}

The impulse signal was generated using a starter pistol, which can produce a strong impulse to noise ratio (INR). At the source to receiver distance of $50 \mathrm{~m}$, the maximum source to receiver distance considered in this study, the INR was $26 \mathrm{~dB}$ at $125 \mathrm{~Hz}, 30 \mathrm{~dB}$ at $250 \mathrm{~Hz}, 38 \mathrm{~dB}$ at 500 $\mathrm{Hz}, 41 \mathrm{~dB}$ at $1000 \mathrm{~Hz}, 47 \mathrm{~dB}$ at $2000 \mathrm{~Hz}$, and $50 \mathrm{~dB}$ at $4000 \mathrm{~Hz}$. According to ISO 3382-2 [25], 


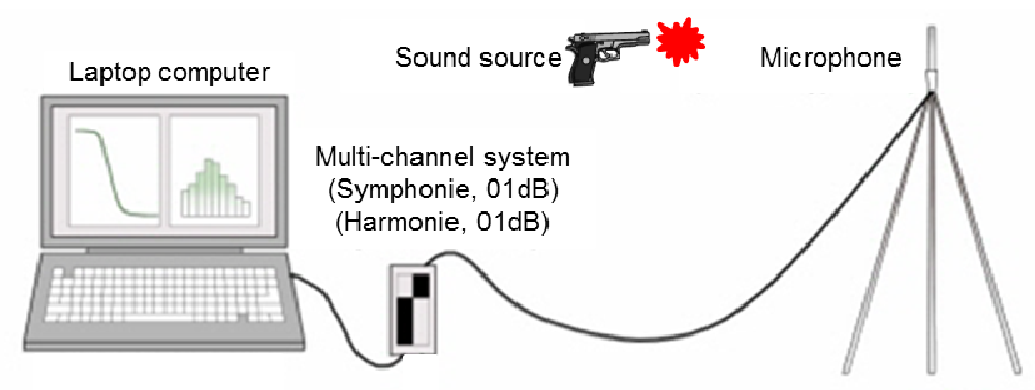

Fig. 5 Illustration of the experimental setup of source, receiver, and FFT analyzer

the recommended INR is at least $35 \mathrm{~dB}$ and $45 \mathrm{~dB}$ for accurate RT measurement of T20 and T30, respectively. Therefore, it can be said that the INR above $500 \mathrm{~Hz}$ is sufficient to calculate T20 for the source to receiver distances within $50 \mathrm{~m}$.

The impulsive signal for the starter pistol was captured using the two-channel Symphonie system $(01 \mathrm{~dB})$ with a $1 / 2$ inch microphone (G.R.A.S. Type MCE 201) and preamplifiers (01dB-Stell Pre $12 \mathrm{H})$. The four channel Harmonie system $(01 \mathrm{~dB})$ was also used with a $1 / 2$ inch microphone (G.R.A.S. Type 40AF) and preamplifiers (G.R.A.S Type 26AG). The receiver and source heights from the ground were $1.5 \mathrm{~m}$. Figure 5 illustrates the experimental condition. Gun shots for each measurement were repeated five times and averaged to calculate the RT.

RT, EDT, $\mathrm{D}_{50}$, and RASTI for the impulse responses recorded from the field measurement were analyzed using the Dirac program from B\&K which has a noise compensation function to reduce the effect of background noise on the RT calculation. In this study, the decay range is selected as T20 ( $-5 \mathrm{~dB}$ to $-25 \mathrm{~dB})$ considering the INR. SPL attenuation with distance was also measured using a directional speaker with a height of $1.5 \mathrm{~m}$. The sound source for the measurement was white noise with the $\mathrm{S} / \mathrm{N}$ of $47 \mathrm{~dB}$ at $1 \mathrm{~m}$ from the source, indicating sufficient sound power to measure SPL attenuation for source to receiver distances within $50 \mathrm{~m}$.

\section{MEASUREMENT RESULTS}

\subsection{Impulse responses and decay curves in 15 outdoor spaces}

To examine the difference in multiple reflection patterns of sound energy in 15 outdoor spaces, it is useful to compare the impulse responses and decay curves measured at the same source to receiver distance. In comparison with a short source to receiver distance, where the direct sound dominants the overall sound energy, an analysis of impulse responses measured at a rather long source to receiver distance could show distinct differences in multiple refection patterns. Thus, Figure 6 and Figure 7 show the impulse responses and corresponding decay curves, respectively, at receiver distances of around $20 \mathrm{~m}$ from a source in 15 outdoor spaces. 


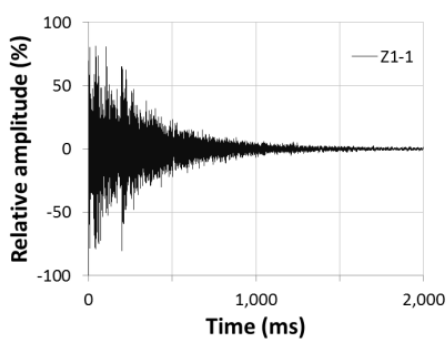

(a) $20 \mathrm{~m} \mathrm{~S}-\mathrm{R}$ dist. at Z1-1(U type)

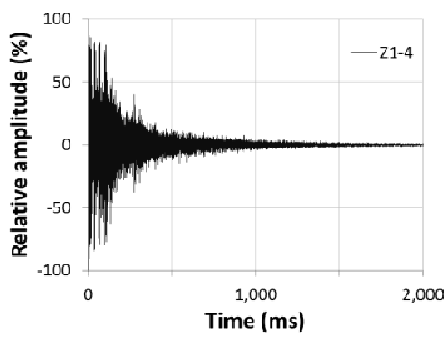

(d) $20 \mathrm{~m} \mathrm{S-R} \mathrm{dist.} \mathrm{at} \mathrm{Z1-4(} \square$ type)

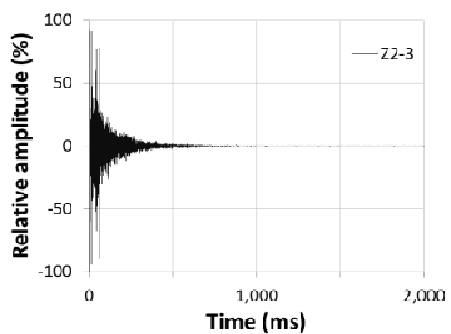

(g) $21 \mathrm{~m} \mathrm{~S}-\mathrm{R}$ dist. at Z2-3(= type)

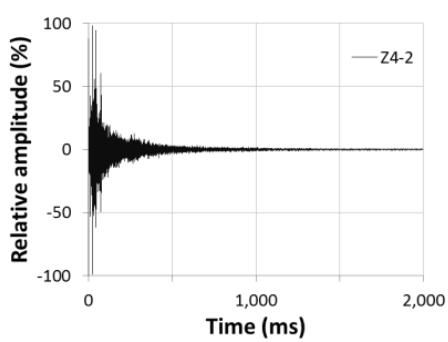

(j) $20 \mathrm{~m} \mathrm{~S}-\mathrm{R}$ dist. at Z4-2(L type)

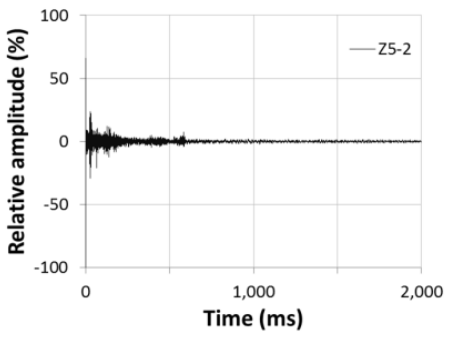

(m) $21 \mathrm{~m} \mathrm{~S}-\mathrm{R}$ dist. at Z5-2(= type)

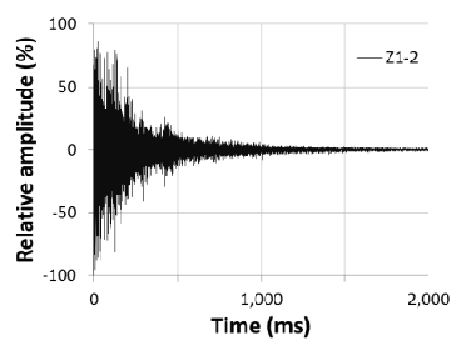

(b) $20 \mathrm{~m} \mathrm{S-R}$ dist. at Z1-2( $\square$ type)

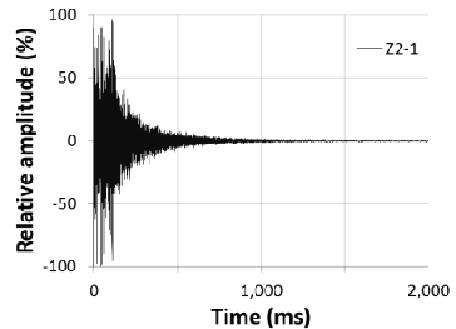

(e) $21 \mathrm{~m} \mathrm{~S}-\mathrm{R}$ dist. at Z2-1(U type)

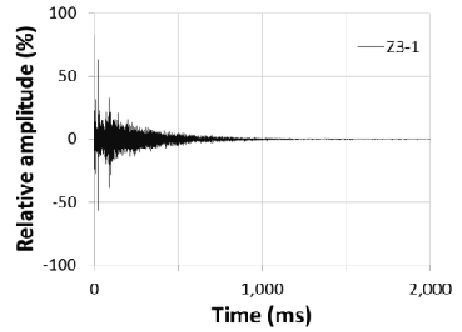

(h) $25 \mathrm{~m} \mathrm{~S}-\mathrm{R}$ dist. at Z3-1( $\square$ type)

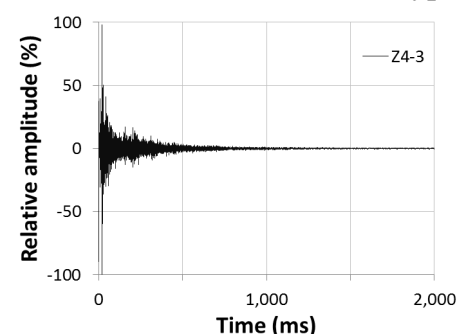

(k) $20 \mathrm{~m} \mathrm{S-R} \mathrm{dist.} \mathrm{at} \mathrm{Z4-3(=} \mathrm{type)}$

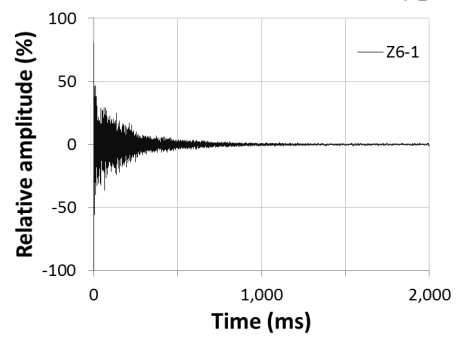

(n) $16 \mathrm{~m} \mathrm{~S}-\mathrm{R}$ dist. at Z6-1 (= type)

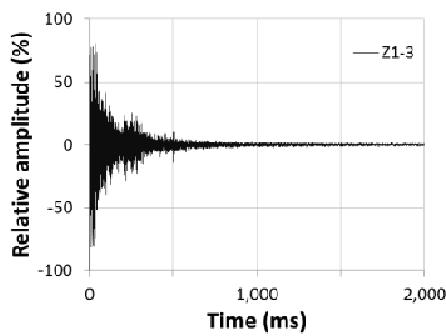

(c) $20 \mathrm{~m} \mathrm{~S}-\mathrm{R}$ dist. at Z1-3(- type)

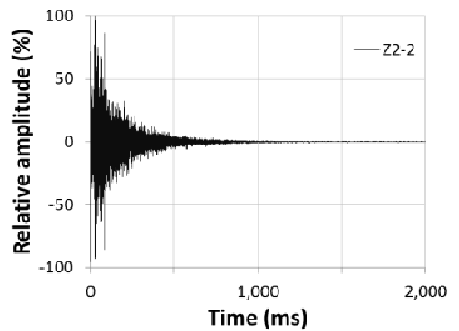

(f) $21 \mathrm{~m} \mathrm{~S}-\mathrm{R}$ dist. at Z2-2(U type)

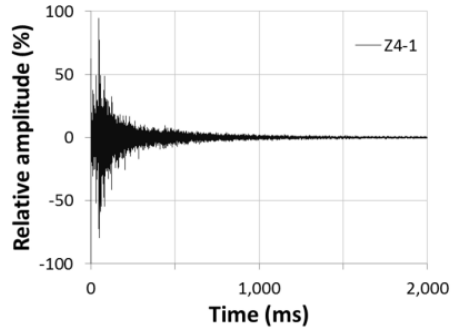

(i) $20 \mathrm{~m} \mathrm{S-R} \mathrm{dist.} \mathrm{at} \mathrm{Z4-1(U} \mathrm{type)}$

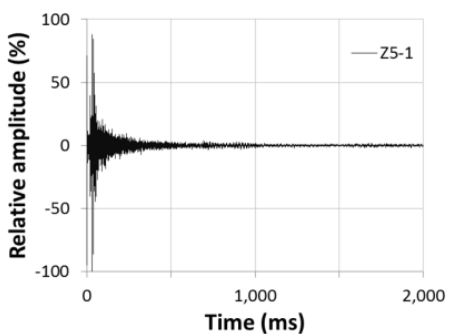

(1) $21 \mathrm{~m} \mathrm{~S}-\mathrm{R}$ dist. at Z5-1(L type)

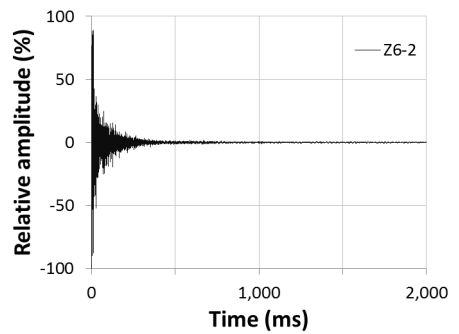

(o) $20 \mathrm{~m} \mathrm{S-R} \mathrm{dist.} \mathrm{at} \mathrm{Z6-2(=} \mathrm{type)}$

Fig. 6 Impulse responses measured at around $20 \mathrm{~m}$ source to receiver distance for 15 outdoor spaces 


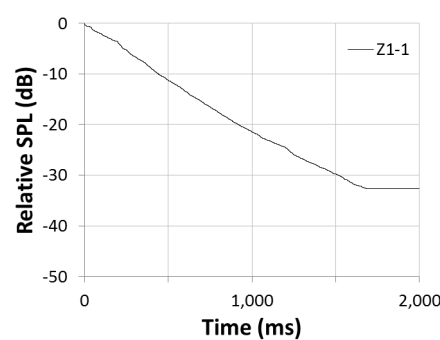

(a) $20 \mathrm{~m} \mathrm{~S}-\mathrm{R}$ dist. at Z1-1(U type)

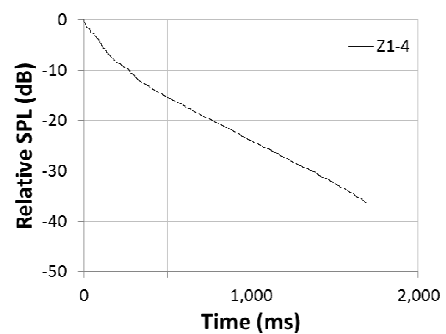

(d) $20 \mathrm{~m} \mathrm{~S}$-R dist. at Z1-4( $\square$ type)

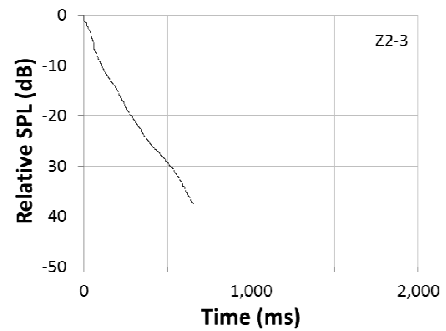

(g) $21 \mathrm{~m} \mathrm{~S}-\mathrm{R}$ dist. at Z2-3(= type)

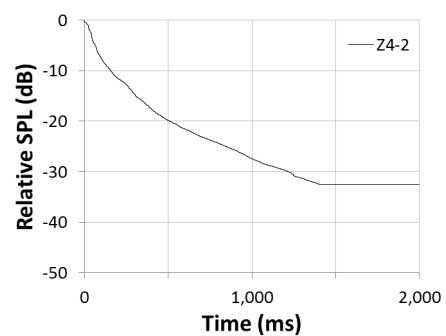

(j) $20 \mathrm{~m} \mathrm{S-R}$ dist. at Z4-2(= type)

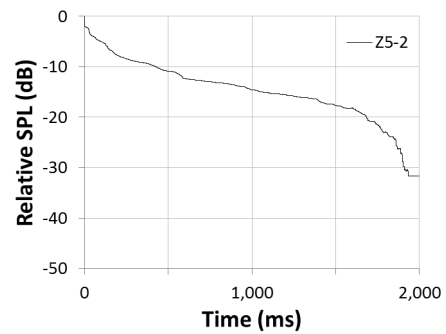

(m) $21 \mathrm{~m} \mathrm{~S}-\mathrm{R}$ dist. at Z5-2(= type)

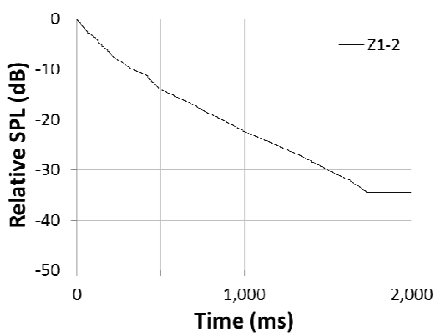

(b) $20 \mathrm{~m} \mathrm{~S}-\mathrm{R}$ dist. at Z1-2( $\square$ type)

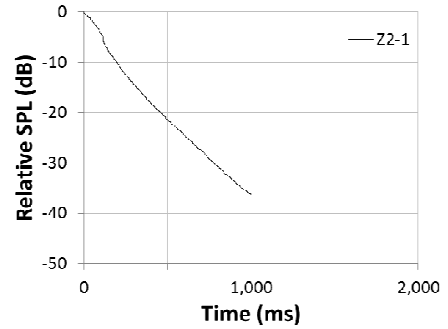

(e) $21 \mathrm{~m} \mathrm{S-R} \mathrm{dist.} \mathrm{at} \mathrm{Z2-1(U} \mathrm{type)}$

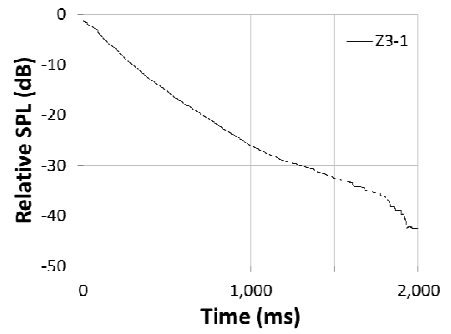

(h) $25 \mathrm{~m} \mathrm{~S}$-R dist. at Z3-1 ( $\square$ type)

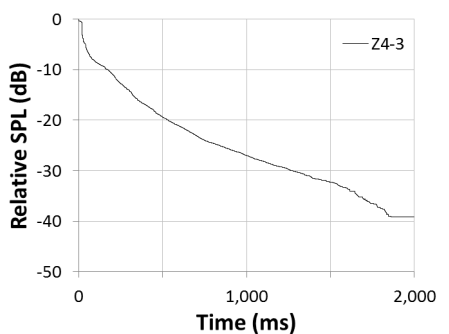

(k) $20 \mathrm{~m} \mathrm{~S}-\mathrm{R}$ dist. at Z4-3(= type)

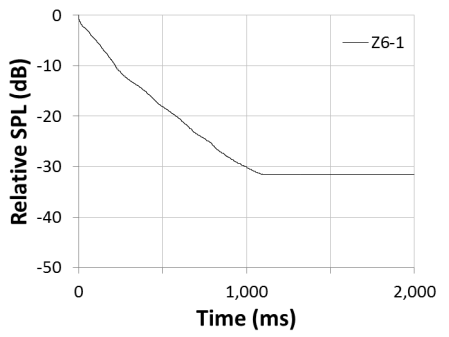

(n) $16 \mathrm{~m} \mathrm{~S}-\mathrm{R}$ dist. at Z6-1 (= type)

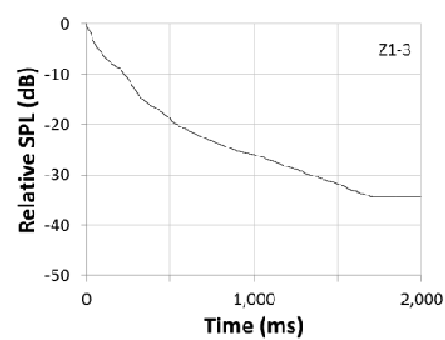

(c) $20 \mathrm{~m} \mathrm{~S}-\mathrm{R}$ dist. at Z1-3(- type)

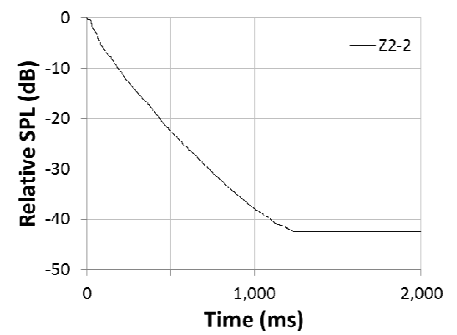

(f) $21 \mathrm{~m} \mathrm{~S}-\mathrm{R}$ dist. at Z2-2(U type)

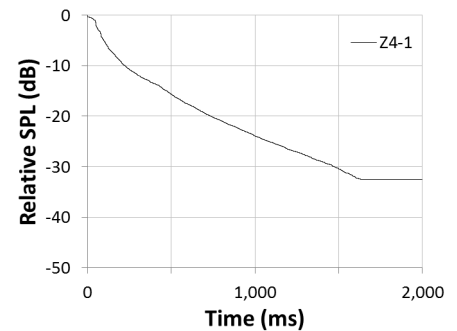

(i) $20 \mathrm{~m} \mathrm{~S}-\mathrm{R}$ dist. at Z4-1(U type)

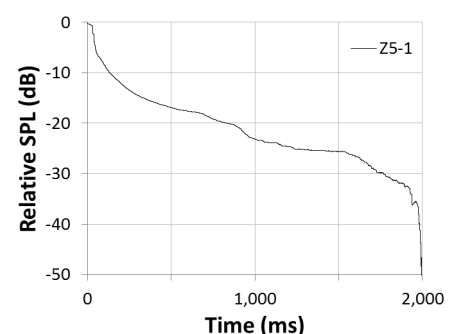

(1) $21 \mathrm{~m} \mathrm{~S}-\mathrm{R}$ dist. at Z5-1(- type)

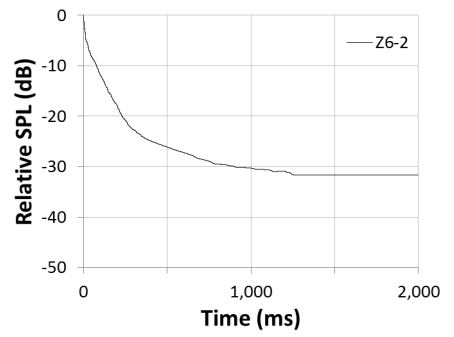

(o) $20 \mathrm{~m} \mathrm{S-R} \mathrm{dist.} \mathrm{at} \mathrm{Z6-2(-} \mathrm{type)}$

Fig. 7 Decay curves measured at around $20 \mathrm{~m}$ source to receiver distance for 15 outdoor spaces 


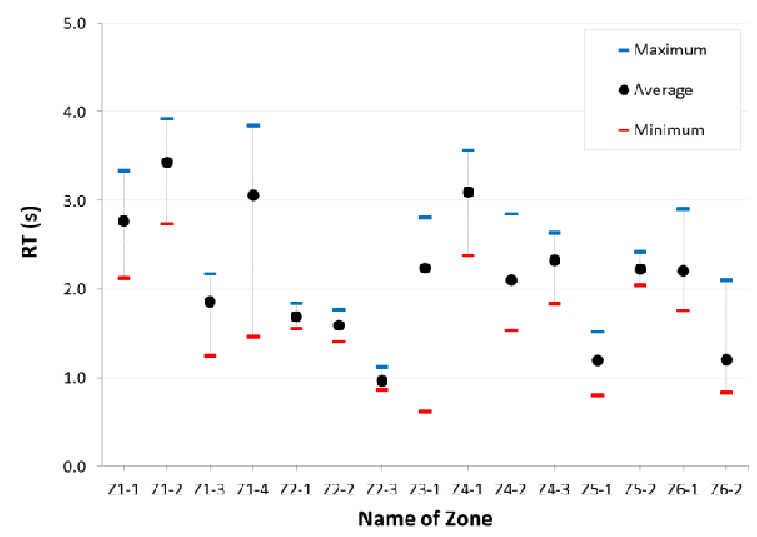

(a) $500 \mathrm{~Hz}$

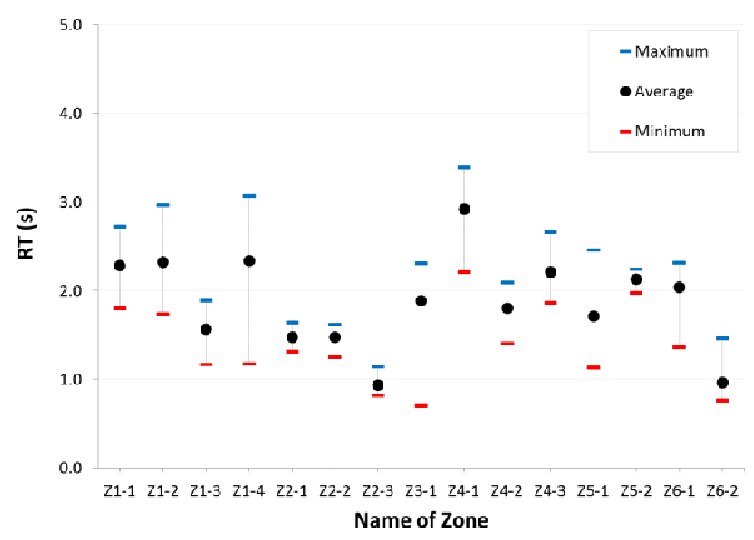

(c) $2000 \mathrm{~Hz}$

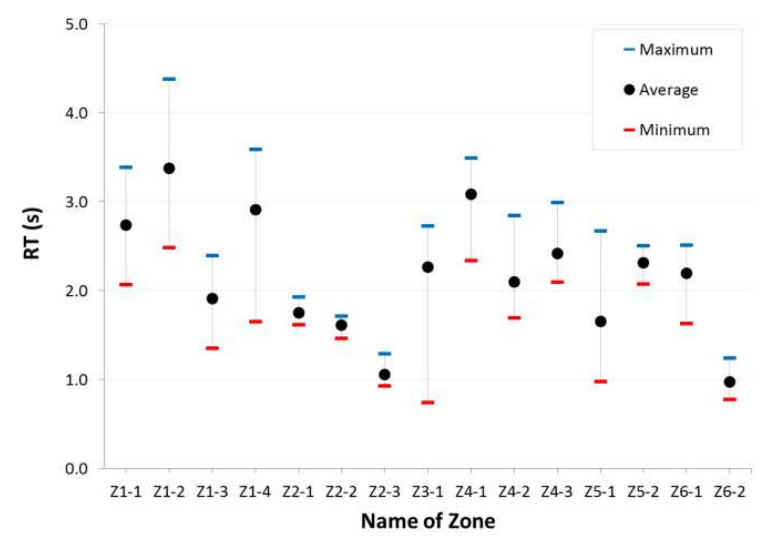

(b) $1000 \mathrm{~Hz}$

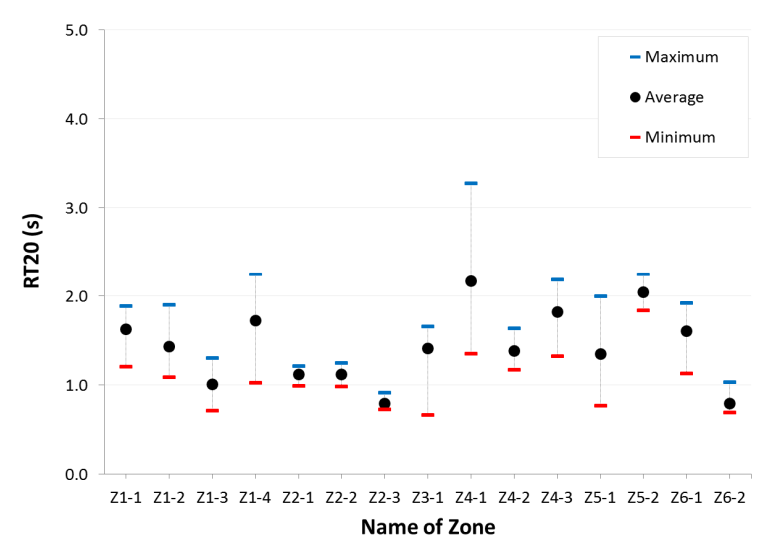

(d) $4000 \mathrm{~Hz}$

Fig. 8 Maximum, average, and minimum RT with frequency between $500 \mathrm{~Hz}$ and $2000 \mathrm{~Hz}$ in the 15 outdoor spaces

The result from Figure 6 shows impulse responses containing strong sound reflections arriving after the direct sound from building façades, ground, and other obstacles such as low-profiled street furniture, barriers, and trees. Thus, it can be said that the reflected sound energy causes increased SPL and RT, related to noise annoyance and spatial impressions. It is noted that the reflection patterns of impulse responses differ among the 15 outdoor spaces, although the measurements were carried out at similar source to receiver distances. This is because the reflection pattern is influenced by many design factors such as building height, building layout, building shape, gaps between buildings, configuration of building façades, the acoustic materials of surfaces, etc. According to the different types of outdoor spaces, reflected sound energy in the $\mathrm{U}$ and $\square$ shapes is relatively strong compared to that in the - and = shapes if the building heights are similar. For example, it can be seen that the reflected sound energy at Z1-1, Z1-2, and Z1-4 is stronger than that at Z1-3, which can be confirmed again from the decay curve in Figure 7.

\subsection{Room acoustical parameters (RT, EDT, $\mathrm{D}_{50}$, and RASTI)}




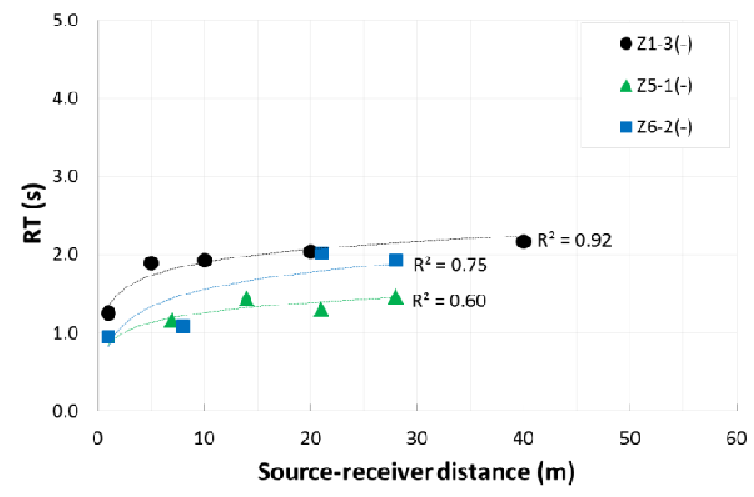

(a) - Type

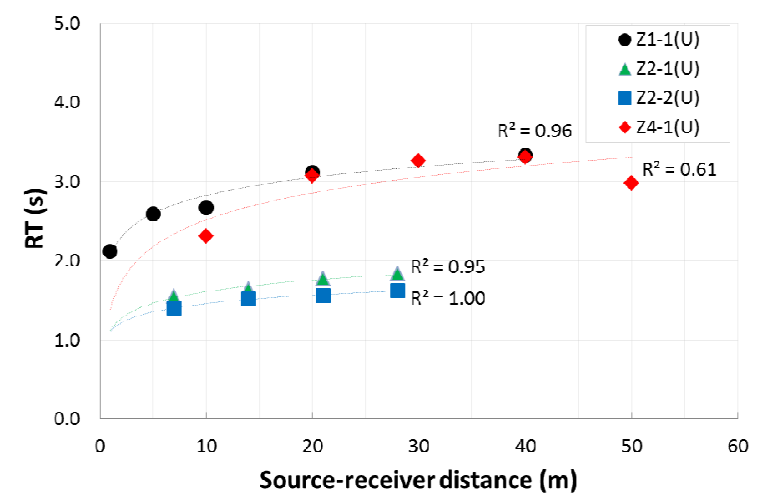

(c) U Type

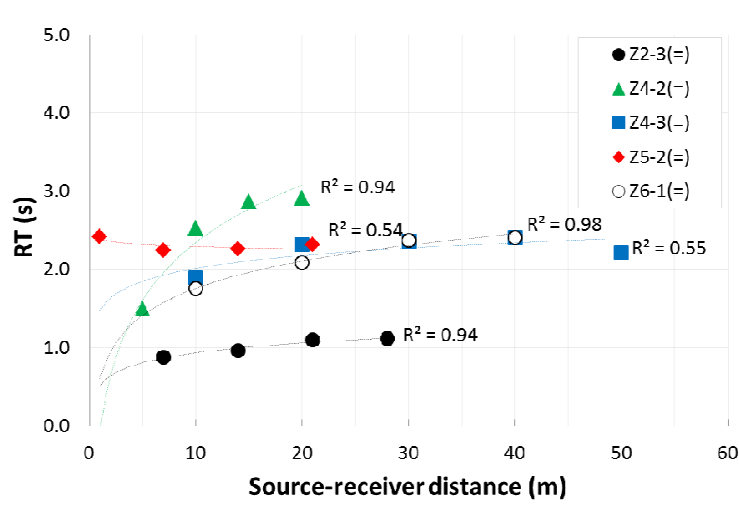

(b) = Type

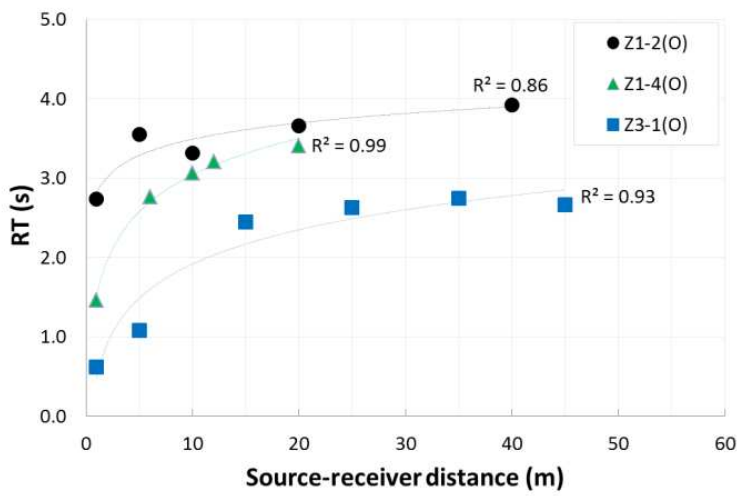

(d) $\square$ Type

Fig. 9 Measured RT at $500 \mathrm{~Hz}$ with different source to receiver distances for 4 different types of building layouts

\subsubsection{RT and EDT}

In Figure 8, the maximum, average, and minimum RT measured in each measurement zone are shown with different frequencies from $500 \mathrm{~Hz}$ to $4000 \mathrm{~Hz}$ in octave band to examine the RT distribution in the outdoor spaces. RT at low frequencies is not presented here due to insufficient INR. The result shows that the differences in RT between maximum and minimum values for each measurement zone are significant at all frequencies, indicating a non-diffuse sound field of the outdoor space with an open ceiling. It can be seen that the maximum, average, and minimum RT differ according to each measurement zone due to the influence of architectural design in the reflection patterns. It is noted that RT is relatively long at $500 \mathrm{~Hz}$ and $1000 \mathrm{~Hz}$ in comparison with other frequencies. Maximum RT at $500 \mathrm{~Hz}$ is found at Z1-2 with about 4 sec.

In urban spaces, the source to receiver distance is an important factor determining RT. In Figure 9, RT at $500 \mathrm{~Hz}$ measured at different source receiver distances in the 15 measurement zones is measured by categorizing the outdoor spaces as the 4 types of building layouts: -, =, $U$, and $\square$. 


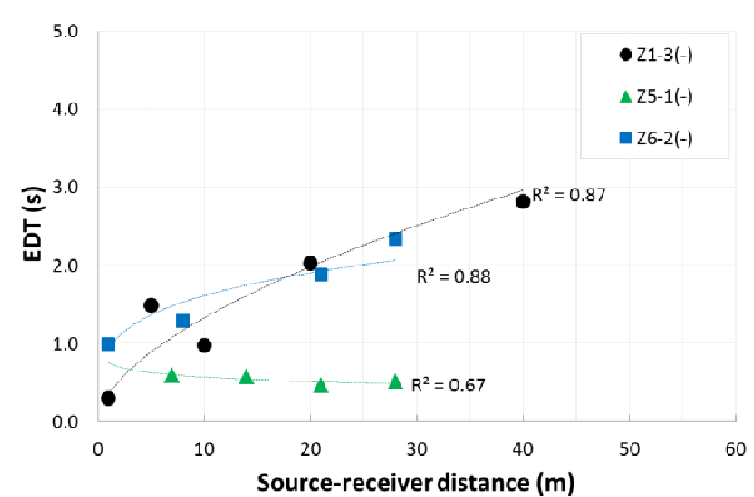

(a) - Type

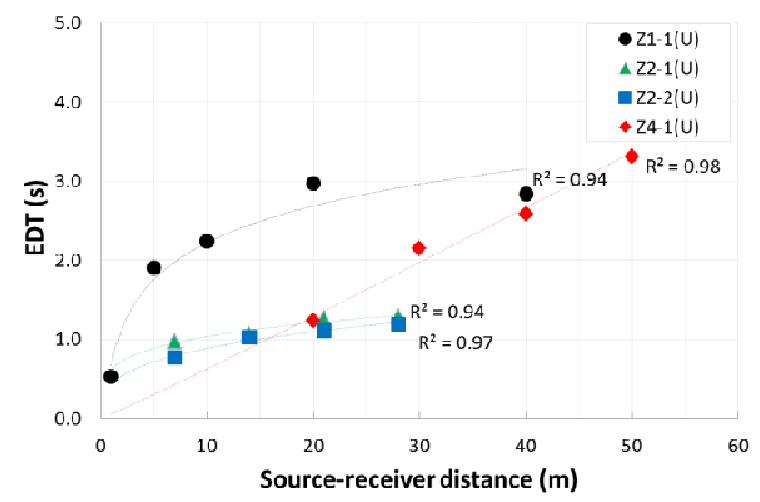

(c) U Type

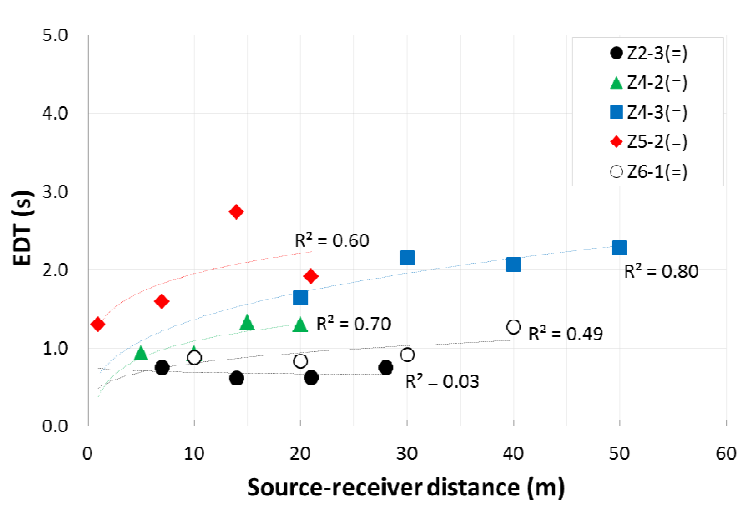

(b) = Type

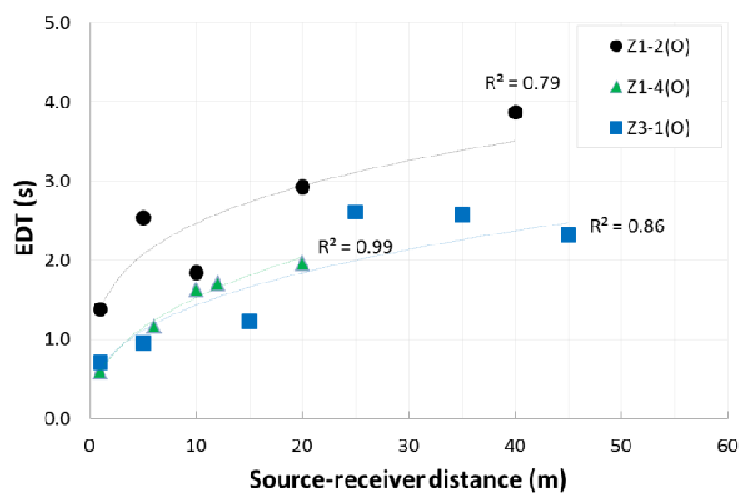

(d) $\square$ Type

Fig. 10 Measured EDT at $500 \mathrm{~Hz}$ with different source to receiver distances for 4 different types of

building layouts

The result shows that RT increases logarithmically with increasing source to receiver distances in all 15 outdoor spaces. This is because the amplitude of the direct sound decreases with increasing source to receiver distances, implying that the influence of reflected sound energy on increasing RT increases with increasing source to receiver distances. The correlation coefficient, $R^{2}$, of the logarithmic regression curve has a relatively high value of between $0.55 \sim 1.00$. It is also shown that RT at the same source to receiver distance has different values due to different architectural designs. For example, Figure 9(c) shows the U type, in which RT at Z2 is relatively short in comparison with that at $\mathrm{Z} 1$ and $\mathrm{Z} 4$ because of the relatively small volume of outdoor space.

In Figure 10, the EDT at each measurement zone is shown according to the source to receiver distances. EDT is a parameter, derived from the decay curve section between $0 \mathrm{~dB}$ and $10 \mathrm{~dB}$ below the initial level. Hence, the sound energy from early reflections has a significant influence on this parameter. The result in Figure 10 shows that EDT tends to increase with increasing 


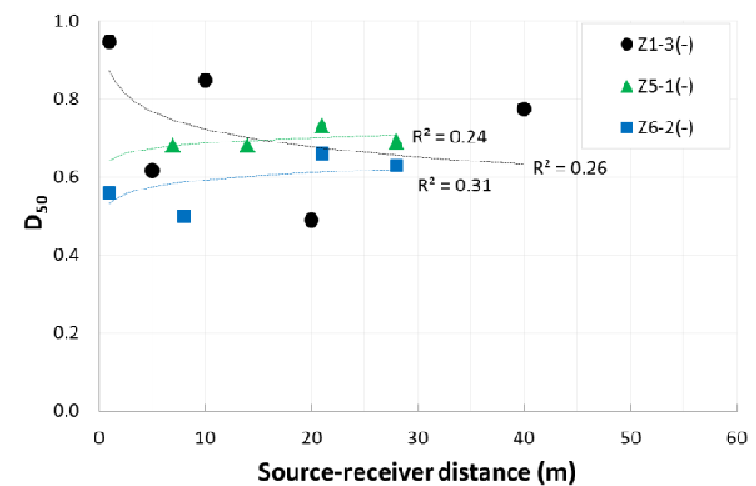

(a) - Type

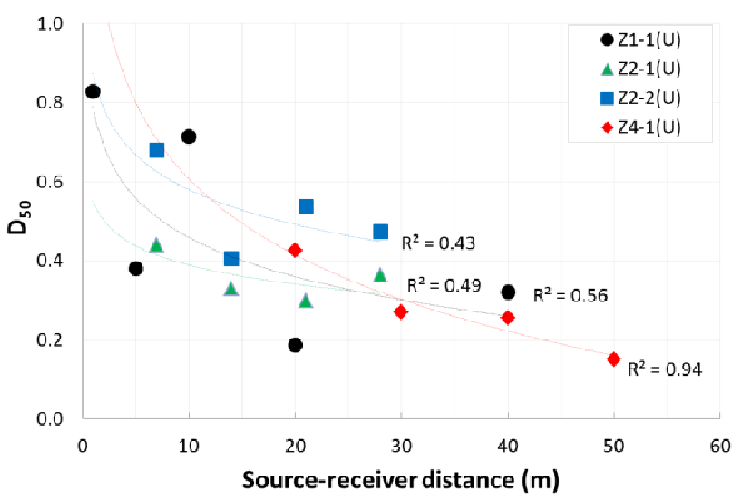

(c) U Type

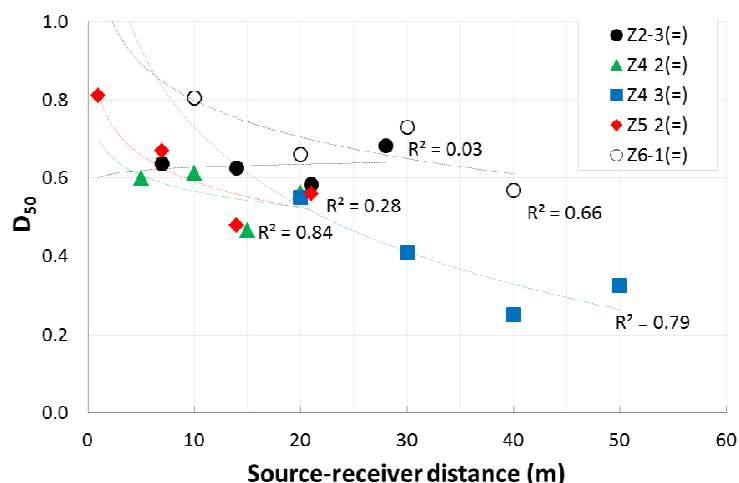

(b) = Type

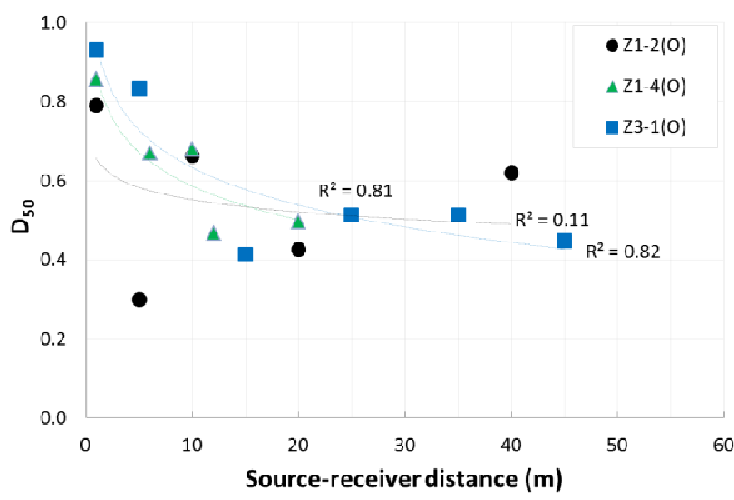

(d) $\square$ Type

Fig. $11 \mathrm{D}_{50}$ with different source to receiver distances for the 4 different types of building layouts

source to receiver distances logarithmically, which is similar to RT. It can also be seen that at the same source to receiver distance, EDT has different values due to the different architectural designs.

\subsubsection{Definition $\left(\mathrm{D}_{50}\right)$}

Energy-related parameters including $\mathrm{D}_{50}$ and Clarity $\left(\mathrm{C}_{80}\right)$ are useful descriptors to investigate how sound energy arrives at the early and late parts of the impulse response. $\mathrm{D}_{50}$ is a parameter related to clarity for speech defined by the ratio of early $(50 \mathrm{~ms})$ to total arriving sound energy measured using a unit of percentage. In this study, $\mathrm{C}_{80}$ is not considered, as it is appropriate for music signals.

Figure 11 shows $D_{50}$ with different source to receiver distances for 4 different types of building layouts. The result shows that, except for a few cases, $\mathrm{D}_{50}$ decreases logarithmically with increasing source to receiver distances. This indicates that with an increasing source to receiver distance, the clarity of speech decreases. The correlation coefficient of regression curves is between 0.03 and 0.94 , which is relatively low compared to that of RT. It is also noted that $\mathrm{D}_{50}$ at 


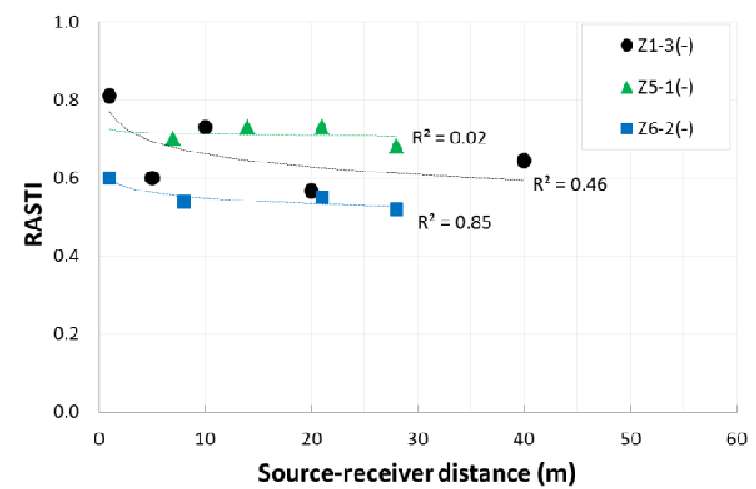

(a) - Type

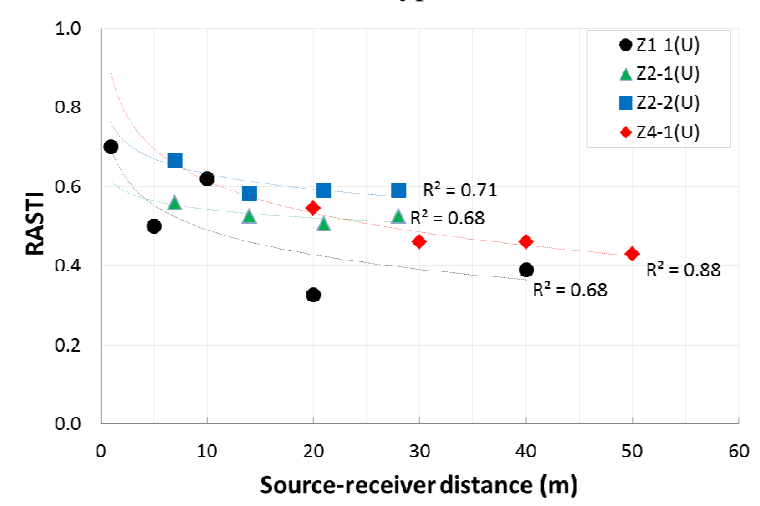

(c) U Type

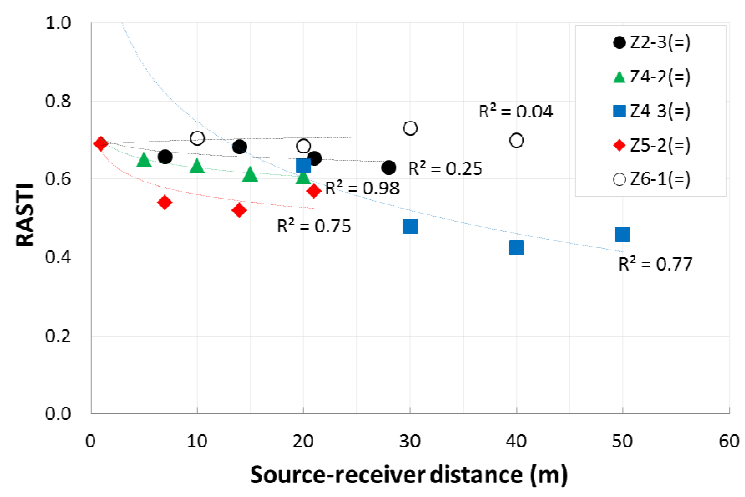

(b) = Type

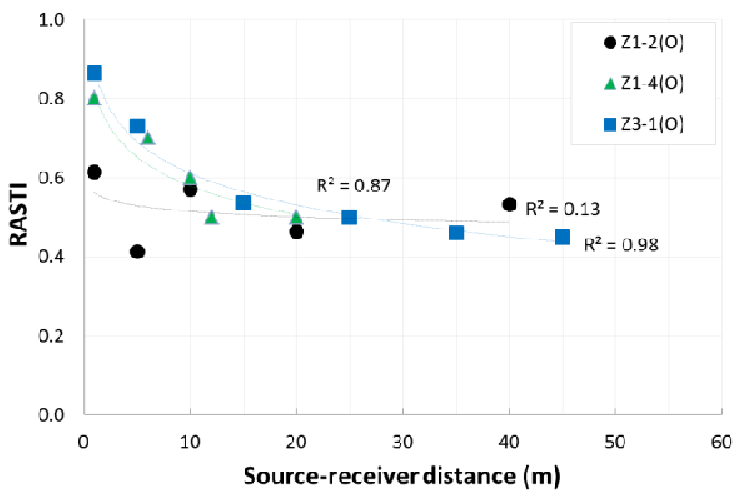

(d) $\square$ Type

Fig. 12 RASTI with different source to receiver distances for the 4 different types of building layouts

the same source to receiver distance varies according to the characteristics of outdoor spaces. For example, $\mathrm{D}_{50}$ at $20 \mathrm{~m}$ source to receiver distance for $\mathrm{U}$ type space has a range between 0.19 and 0.57 , showing the importance of selecting the correct design for the outdoor layout.

\subsubsection{RASTI}

Acoustic descriptors related to speech intelligibility such as RASTI provide useful information on the design of public address (PA) systems that announce notices to the residents in an outdoor space of an apartment complex. In this study, the RASTI in the outdoor spaces is measured according to the source to receiver distances to examine speech intelligibility evaluated according to 5 grades: $0-0.3$, very poor; $0.3-0.45$, poor; $0.45-0.6$, fair; $0.6-0.75$, good; $0.75-1.0$, excellent [26].

As shown in Figure 12, it can be seen that RASTI tends to decrease with the increase of distance, which is similar to the result to $\mathrm{D}_{50}$. This is because within a short source to receiver distance, the direct sound dominates the early sound energy of the impulse response, resulting in a short RT, while RT increases with increased distance due to the decreased amplitude of the direct sound. 


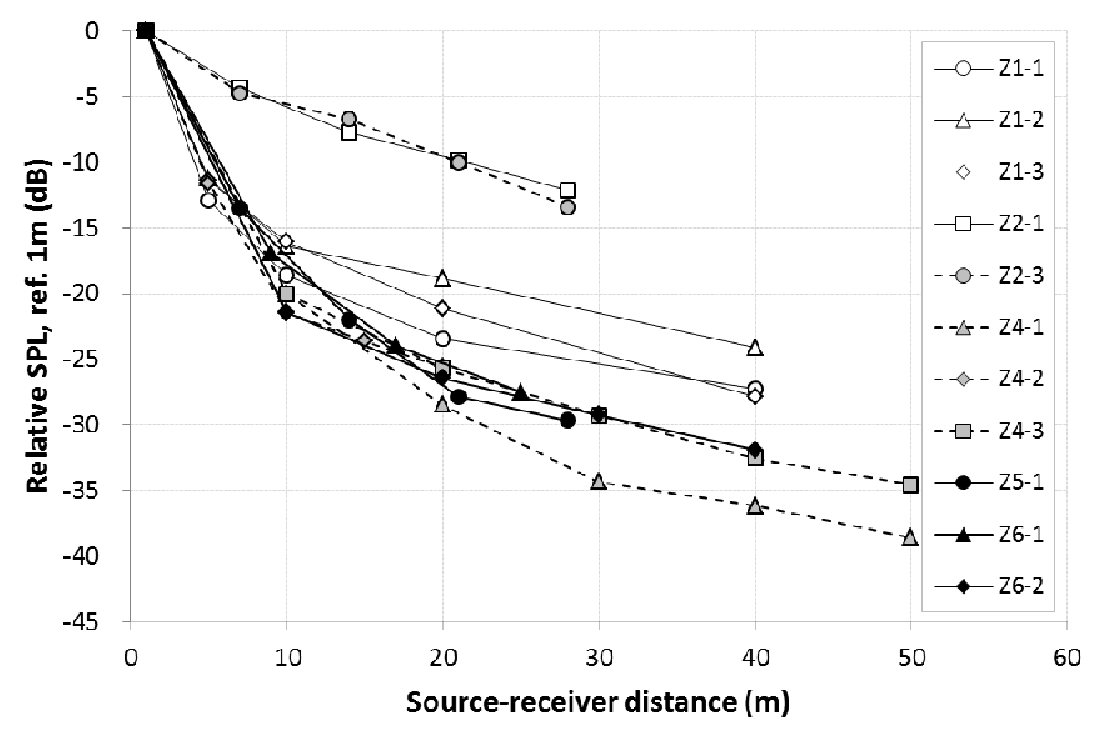

Fig. 13 SPL attenuation according to source to receiver distance in 11 outdoor spaces

Based on the result shown in Figure 12, it is concluded that the design of PA systems needs to be changed to consider the characteristics of the building layouts surrounding an outdoor space.

\subsection{SPL attenuation}

The characteristics of SPL attenuation in outdoor spaces provide useful information about the way in which the multiple reflections from the surrounding geometry enhance SPL at a certain receiver point from a sound source. The enhanced sound energy implies an increased noise annoyance for the residents in outdoor spaces as well as in living rooms, especially during summer when using natural ventilation.

Figure 13 shows the result of SPL attenuation relative to the reference SPL measured at a source to receiver distance of $1 \mathrm{~m}$ in 11 outdoor spaces. The result shows that in all of the outdoor spaces, SPL decreases with increasing source to receiver distance due to the characteristics of the non-diffuse field. It can also be seen that SPL attenuation at the same source to receiver point varies with the different characteristics of the surrounding geometry. For example, at a source to receiver distance of around $20 \mathrm{~m}, \mathrm{SPL}$ attenuation ranges between -9.8 and $-28.5 \mathrm{~dB}$, indicating a $17.7 \mathrm{~dB}$ difference due to the surrounding building geometry. The outdoor space of Z2-3 has an SPL attenuation of $-9.8 \mathrm{~dB}$, with a low value in building height, gaps between buildings, and volume, while Z4-1 showed an SPL attenuation of $-28.5 \mathrm{~dB}$ due to high values for the architectural design factors. The overall result indicates that architectural design significantly affects the level of noise annoyance experienced by residents. 


\section{EMPRICAL METHOD TO PREDICT RT AND SPL ATTENATION}

\subsection{RT}

It is well known from Sabine's equation that the volume and absorption power of a space play an important role in determining RT. In comparison with the diffuse sound field in enclosed rooms, outdoor spaces have a non-diffuse sound field mainly due to the open ceiling and gaps between buildings which can be treated as surfaces with the absorption coefficient of 1.0. Generally, apartment buildings consist of concrete walls and windows with acoustically flat and reflective surfaces. Therefore, it is expected that the openness of an outdoor space is an important factor determining RT. In terms of volume, the size of an outdoor space as well as the building height can have an influence on RT.

To evaluate the openness and size-related parameters of an outdoor space, in this study, a raytracing technique is applied by drawing 360 rays ( 1 degree between rays) emitted from a sound source, which can be easily drawn in AutoCAD. The location of a sound source is determined considering the point measured at each measurement zone. The openness of an outdoor space is calculated by the percentage of the effective rays that reach building façades within a boundary line of the outdoor spaces. A distance threshold between the source, the façade, and the source is defined as $170 \mathrm{~m}$ by assuming a maximum $\mathrm{S} / \mathrm{N}$ of $45 \mathrm{~dB}$ in outdoor spaces at a $1 \mathrm{~m}$ source to receiver distance, which is a comparative value for sound attenuation for $170 \mathrm{~m}$ in a semi-free field. The maximum $\mathrm{S} / \mathrm{N}$ of $45 \mathrm{~dB}$ is determined by considering shouted speech $(85 \mathrm{dBA}$ at $1 \mathrm{~m})$ and quiet outdoor background noise ( $40 \mathrm{dBA})$. Size-related parameters including total ray length, average ray length, closed area, and closed volume for the effective ray are also calculated to investigate the relationship between design factors and RT. The definition and calculation method of each design factor are given as follows.

- Openness: 1 - (Number of effective rays on building façades/360)

- Total ray length (m): Sum of the effective ray length

- Average ray length (m): Total ray length/Number of effective rays

- Closed area $\left(\mathrm{m}^{2}\right)$ : Sum of area closed by rays and façades

Closed volume $\left(\mathrm{m}^{3}\right)$ : Closed area $\times$ building height

Figure 14 shows an example of the method used to calculate the size-related parameters by drawing the effective rays at Z1-1. Table 3 describes the design factors including openness, building height, and the size-related parameters for each measurement zone.

Figure 15 shows the relationship between openness and RT. RT in Figure 15 is the value measured at the source to receiver distance of around $20 \mathrm{~m}$ from which RT changes insignificantly with increasing source to receiver distance. The result shows that the correlation 


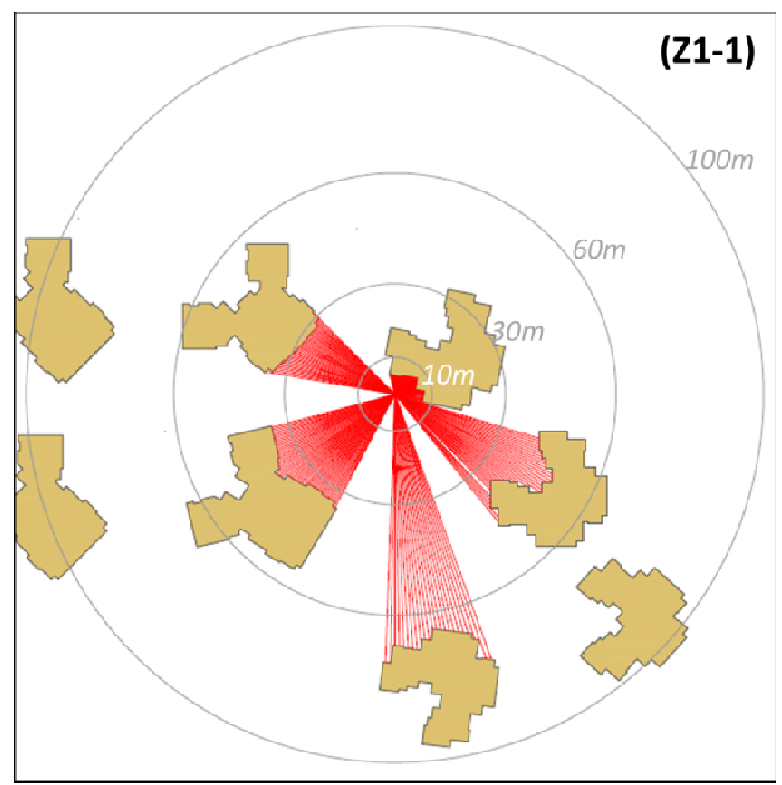

Fig. 14 Example of the calculation method for effective ray and size-related parameters at Z1-1

Table 3 Description of design factors including openness, building height, and the size-related parameters for each measurement zone

\begin{tabular}{|c|c|c|c|c|c|c|c|}
\hline $\begin{array}{l}\text { Measurement } \\
\text { zone }\end{array}$ & $\begin{array}{c}\text { No. of } \\
\text { effective } \\
\text { rays }\end{array}$ & Openness & $\begin{array}{l}\text { Total } \\
\text { ray length } \\
\text { (m) }\end{array}$ & $\begin{array}{l}\text { Averaged } \\
\text { ray length } \\
(\mathrm{m})\end{array}$ & $\begin{array}{c}\text { Closed } \\
\text { area } \\
\left(\mathrm{m}^{2}\right) \\
\end{array}$ & $\begin{array}{c}\text { Closed } \\
\text { volume } \\
\left(\mathrm{m}^{3}\right)\end{array}$ & $\begin{array}{c}\text { Building } \\
\text { height } \\
(\mathrm{m})\end{array}$ \\
\hline Z1-1 & 260 & 0.28 & 7189 & 27.6 & 2685 & 104726 & 39 \\
\hline $\mathrm{Z} 1-2$ & 242 & 0.33 & 6803 & 28.1 & 2733 & 106587 & 39 \\
\hline Z1-3 & 143 & 0.60 & 4613 & 32.3 & 2135 & 83265 & 39 \\
\hline Z1-4 & 306 & 0.15 & 8992 & 29.4 & 3065 & 119535 & 39 \\
\hline Z2-1 & 335 & 0.07 & 4245 & 12.7 & 896 & 18816 & 21 \\
\hline Z2-2 & 349 & 0.03 & 4005 & 11.5 & 643 & 7716 & 12 \\
\hline Z2-3 & 167 & 0.54 & 2059 & 12.3 & 254 & 3048 & 12 \\
\hline Z3-1 & 305 & 0.15 & 6585 & 21.6 & 2154 & 77544 & 36 \\
\hline Z4-1 & 194 & 0.46 & 6631 & 34.2 & 2566 & 161658 & 63 \\
\hline Z4-2 & 272 & 0.24 & 5581 & 20.5 & 1542 & 107940 & 70 \\
\hline Z4-3 & 206 & 0.34 & 7080 & 34.4 & 2833 & 127485 & 45 \\
\hline Z5-1 & 172 & 0.52 & 1349 & 7.8 & 117 & 4914 & 42 \\
\hline Z5-2 & 143 & 0.60 & 5323 & 37.2 & 2889 & 121338 & 42 \\
\hline Z6-1 & 221 & 0.39 & 6673 & 30.2 & 3448 & 139644 & 40 \\
\hline Z6-2 & 171 & 0.53 & 2950 & 17.3 & 1273 & 57285 & 45 \\
\hline
\end{tabular}




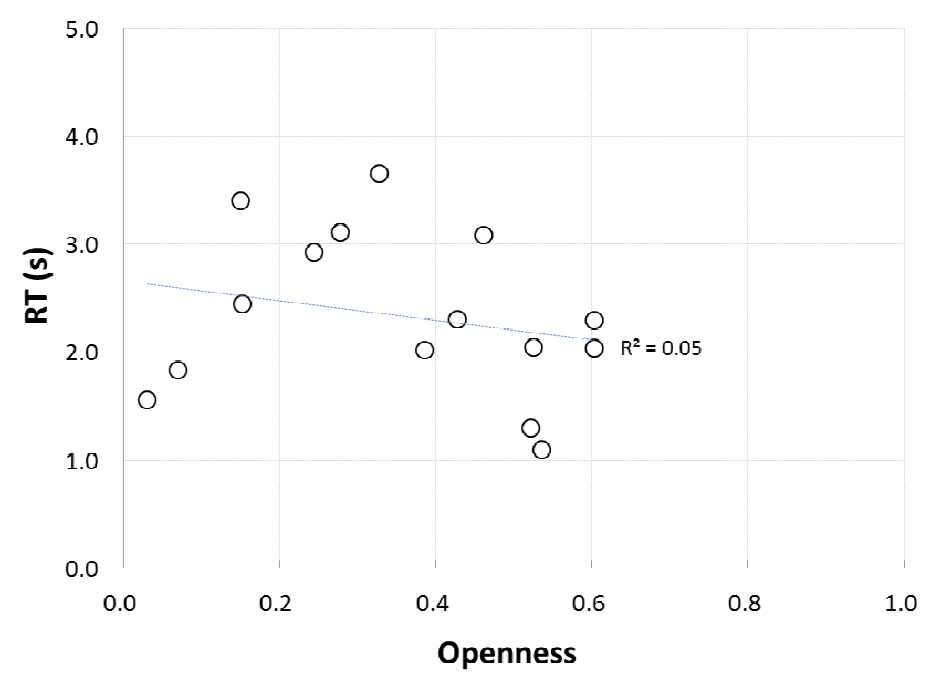

Fig. 15 Correlation analysis between openness and RT measured at a $20 \mathrm{~m}$ source to receiver distance ( $p$ -

$$
\text { value }=0.413)
$$

coefficient between RT and openness is 0.05 with a $p$-value of 0.413 , indicating a low correlation due to the influence of the variation in width and height of each outdoor space.

Figure 16 shows the results of correlation analysis to examine the relationship between RT and size-related parameters including total ray length, average ray length, closed area, and closed volume. The result shows that RT tends to increase with increasing value of the size-related parameters. The high correlation coefficient and low $p$-value indicate that the size-related parameters play an important role in determining RT in outdoor spaces. Particularly, it can be seen that three size-related parameters including total ray length, closed area, and closed volume show very strong correlation because $p$-value approaches less than 0.001 . It is also observed that the closed volume has the highest correlation coefficient with RT. Therefore, it can be said that the empirical equation related to the size-related parameters provides a useful tool to approximate RT at a $20 \mathrm{~m}$ source to receiver distance.

Although the proposed empirical equation used to predict an approximate RT in the outdoor spaces with non-diffuse sound field has a limitation in terms of accuracy, this simple calculation method could provide a useful tool in the design stage for architects to predict RT.

\subsection{SPL attenuation}

In a diffuse sound field, SPL in a room is calculated using Eq. 4.1, combining the direct field contribution with the reverberant field contribution to the sound pressure.

$$
\mathrm{L}_{\mathrm{p}}=\mathrm{L}_{\mathrm{W}}+10 \log _{10}\left[\frac{\mathrm{Q}}{4 \pi \mathrm{r}^{2}}+\frac{4}{\mathrm{R}}\right]
$$




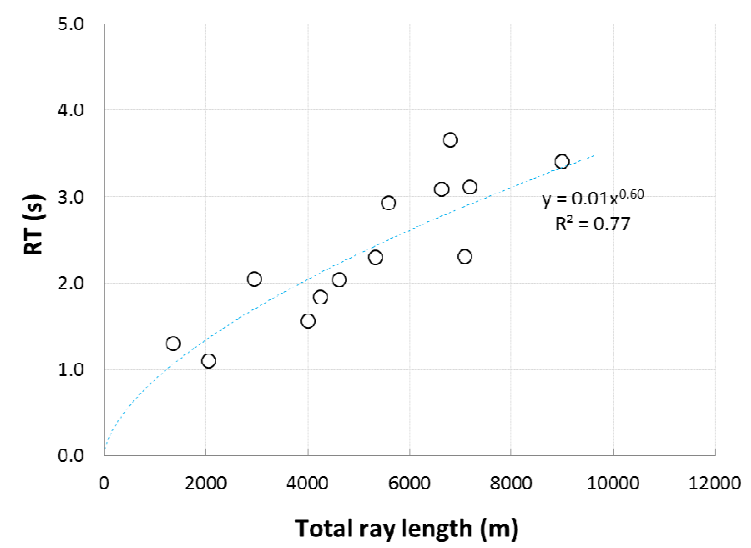

(a) Total ray length $(p$-value $<0.001)$

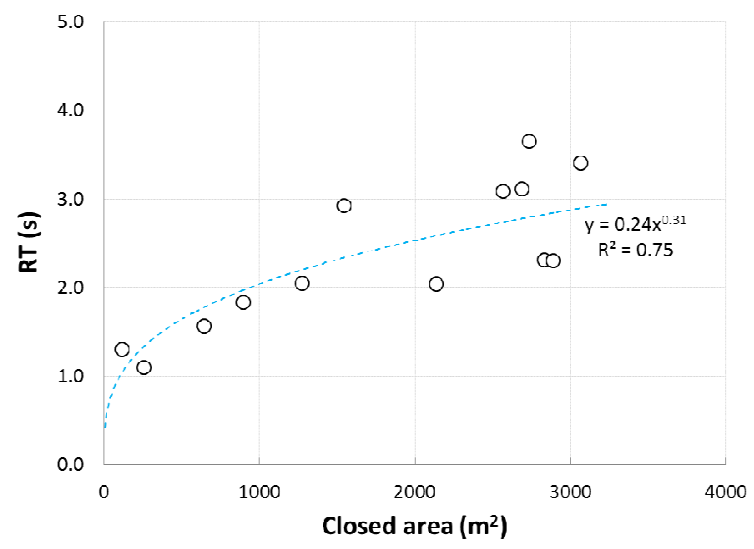

(c) Closed area $(p$-value $<0.001)$

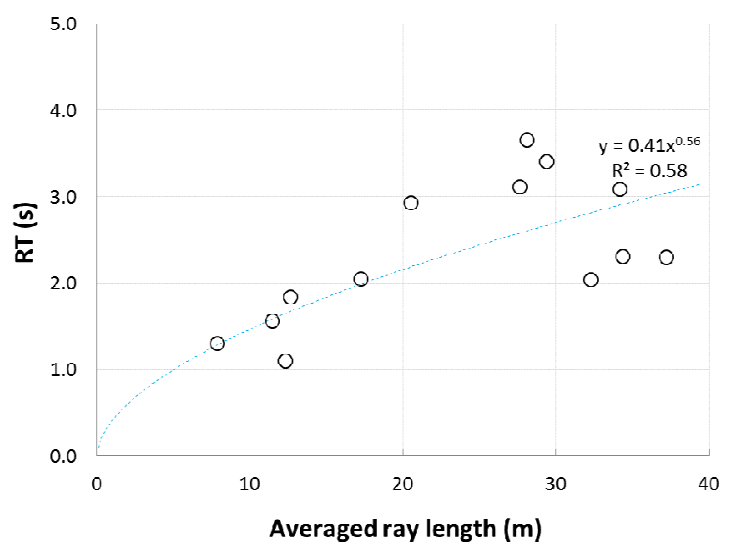

(b) Averaged ray length $(p$-value $=0.016)$

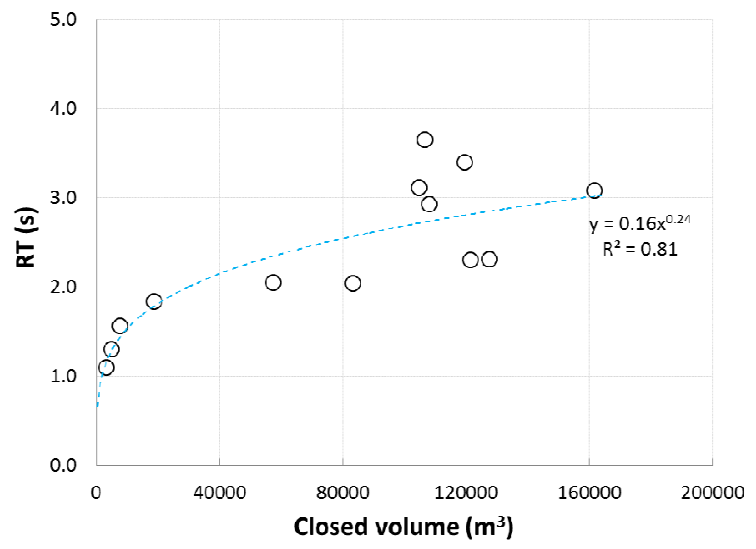

(d) Closed volume ( $p$-value $<0.001)$

Fig. 16 Correlation analysis between the size-related parameters and RT measured at a $20 \mathrm{~m}$ source to receiver distance

where

$\mathrm{L}_{\mathrm{p}}=$ sound pressure level, $\mathrm{dB}$

$\mathrm{L}_{\mathrm{w}}=$ sound power level, $\mathrm{dB}$

$\mathrm{Q}=$ directivity factor

$\mathrm{r}=$ distance from the source, $\mathrm{m}$

$\mathrm{R}=\frac{\mathrm{S} \bar{\propto}}{(1-\bar{\propto})}=$ the room constant, $\mathrm{m}^{2}$ 


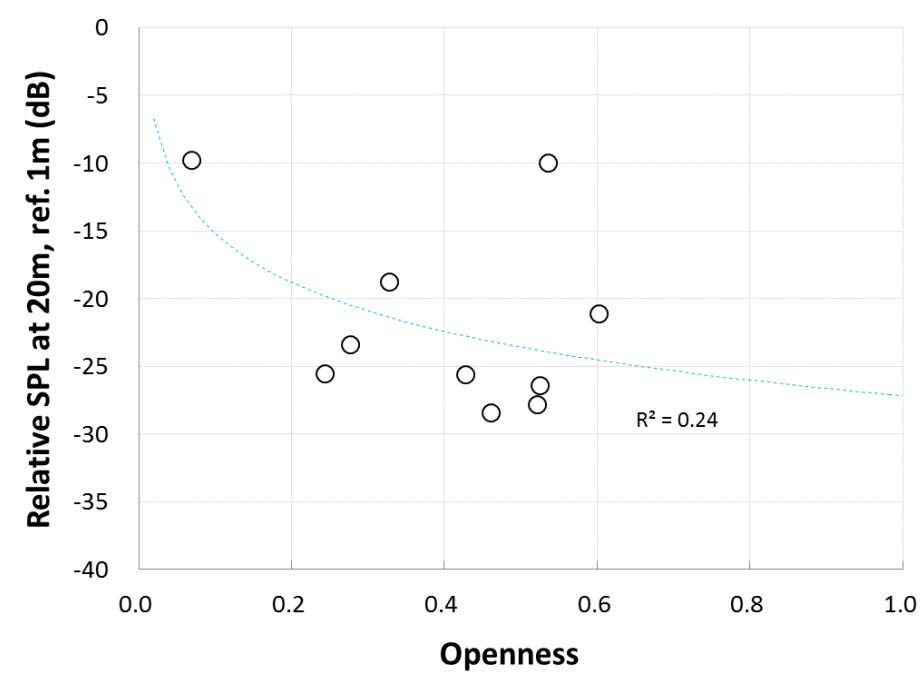

Fig. 17 Correlation analysis between openness and SPL attenuation measured at a $20 \mathrm{~m}$ source to receiver distance $(p$-value $=0.337)$

$$
\begin{aligned}
& \bar{\alpha}=\text { average Norris-Eyring absorption coefficient } \\
& \mathrm{S}=\text { total area of the absorbent surfaces }, \mathrm{m}^{2}
\end{aligned}
$$

Eq. 4.1 indicates that SPL with the direct field is determined using the distance from the source and directivity factor, while SPL in the reverberant field is determined from the room constant influenced by the surface absorption. Therefore, it can be assumed that SPL at a receiver point in an outdoor space is mainly influenced by the amount of surface absorption.

Figure 17 shows the relationship between openness and SPL attenuation measured at a $20 \mathrm{~m}$ source to receiver distance in 10 outdoor spaces to examine the influence of absorption quantified by openness, which can be treated as the absorption coefficient of 1.0. The result indicates that the correlation coefficient between SPL attenuation and openness is as low as 0.24 with a $p$-value of 0.337 , although the coefficient is higher than that between $\mathrm{RT}$ and openness.

To reflect the surface area with an absorption coefficient of 1.0, the surface area of the gaps between buildings needs to be calculated, as well as that of the open ceiling, if the extra boundary such as building façades and ground is assumed as surfaces with an absorption coefficient of 0 . However, calculating the area of the open surface is difficult due to the complicated geometry. In this study, it is therefore assumed that the area of the open surface is proportional to the building height. Based on this, a new parameter called the weighted room constant is suggested as given in Eq. 4.2. 


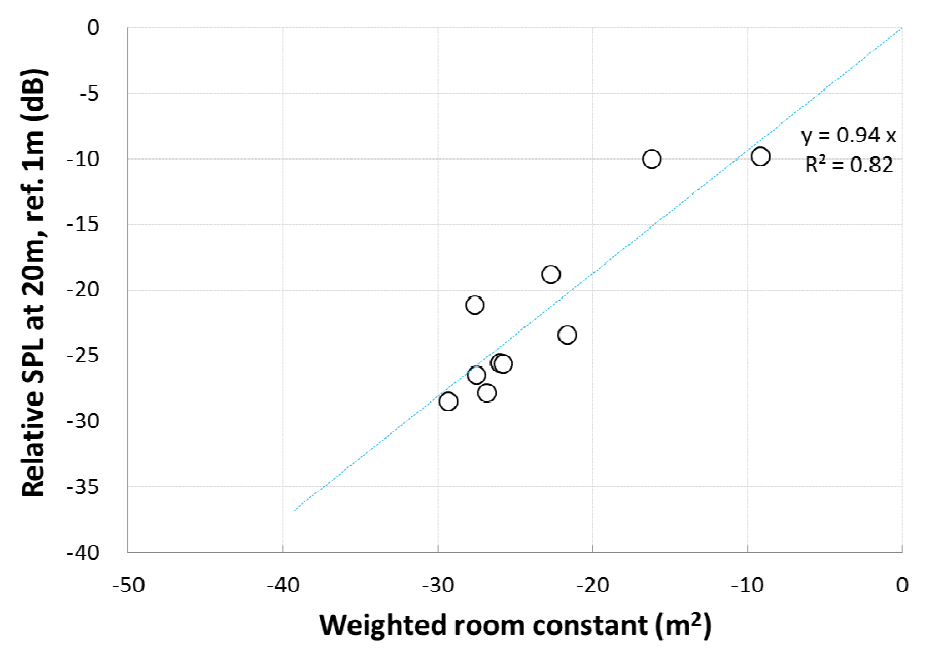

Fig. 18 Correlation analysis between weighted room constant and SPL attenuation measured at a $20 \mathrm{~m}$ source to receiver distance $(p$-value $<0.001)$

$R^{\prime}$ (weighted room constant $)=10 \log _{10}\left[\frac{4}{\frac{h^{2} \times \text { openness }}{(1-\text { openness })}}\right]$

where $\mathrm{h}(\mathrm{m})$ is building height.

Figure 18 shows the relationship between the weighted room constant and SPL attenuation measured at a $20 \mathrm{~m}$ source to receiver distance. As shown in Figure 18, the correlation between the weighted room constant and SPL attenuation is very strong, since the $p$-value is less than 0.001. It can be seen that with the increase of the weighted room constant, SPL is less attenuated. The high correlation indicates that the weighted room constant is a useful descriptor to predict the increased SPL in an outdoor space.

\section{DISCUSSION AND CONCLUSIONS}

In this study, a series of field measurements for SPL attenuation and room acoustical parameters including RT, EDT, $\mathrm{D}_{50}$, and RASTI were carried out for 15 outdoor spaces in 6 apartment complexes, which were determined by considering the different building layouts, blocks, sizes, and heights for a parametric study. Based on the data from field measurements, an empirical method determining RT and SPL attenuation is also suggested. 
The result for RT distribution indicated that RT is significantly influenced by the source to receiver distance, building layout, and sizes of buildings. It was demonstrated that a maximum RT at $500 \mathrm{~Hz}$ and $1000 \mathrm{~Hz}$ is relatively long, about $4 \mathrm{sec}$, which shows the outdoor spaces are reverberant due to multiple reflections between building façades with specula surfaces. RT was distributed with a high deviation in the same outdoor space, showing a non-diffused sound field mainly due to the open ceiling and gaps between buildings. With increasing source to receiver distance, RT is generally increased logarithmically. It was also found that RT tends to rapidly change at a short distance from the sound source due to the strong effect of the direct sound. On the other hand, the change in RT above a source to receiver distance of about $15 \mathrm{~m}$ was insignificant. EDT also showed a similar tendency as that of RT. It was also shown that $\mathrm{D}_{50}$ and RASTI tend to decrease with the increase of source to receiver distances. At the same source to receiver distance in 15 outdoor spaces, $\mathrm{D}_{50}$ and RASTI also varied significantly due to the influence of the building geometry. The measurement result for SPL attenuation showed a difference of $17.7 \mathrm{~dB}$ between the 11 outdoor spaces in the SPL at a $20 \mathrm{~m}$ source to receiver distance measured due to the characteristics of the surrounding building geometry.

By using AutoCAD, in this study, RT and SPL attenuation were predicted with an empirical model considering openness and size-related parameters. It was shown that RT is strongly influenced by size-related parameters, including total ray length, closed area, and closed volume. On the other hand, SPL attenuation had a strong relationship with the absorption power of the space, which was quantified with the new design factor called weighted room constant. The overall result indicated that the empirical model used to predict RT and SPL attenuation is a useful tool for architects during the design process to understand how a space affects the reverberance and noise annoyance due to the increased SPL by the surrounding building geometry.

Although the acoustic characteristics of outdoor spaces surrounded by high-rise residential buildings were investigated in this study by a series of measurements, it is still necessary to carry out more systematic studies by using simulation techniques to suggest design guidelines for outdoor sound environments according to the size and volume of the spaces. Also, subjective evaluation on a spatial impression of the outdoor spaces needs to be carried out using spaciousness parameters such as inter-aural cross correlation coefficient (IACC), apparent source width (ASW), listener envelopment (LEV), etc. Another topic of interest is the effect of audiovisual interaction in outdoor spaces on noise annoyance. It is expected that the proposed topics could provide useful information on the design of a comfortable level of sound for environments in outdoor spaces.

\section{ACKNOWLEGEMENTS}

This research was supported by Basic Science Research Program through the National Research Foundation of Korea (NRF) funded by the Ministry of Education, Science and Technology (No. Applied Acoustics, Volume 127,2017, Pages 147-159 
2011-0007171). A part of this research is also the result of the research carried out in the cooperation project of the industry-academia-government in Seoul (project identification number: PSI160001) (project name: Urban problem solving technology development support project).

\section{REFERENCES}

[1] H. S. Baik, "Creating outdoor space for everyday life in multi-family housing estate", Doctoral thesis, Yonsei University, (2003)

[2] S. Castiñeira-Ibañez, C. Rubio and J. V. Sánchez-Pérez, "Environmental noise control during its transmission phase to protect buildings. Design model for acoustic barriers based on arrays of isolated scatterers", Build Environ, 93, 179-185, (2015)

[3] M. Hornikx and J. Forssén, "Noise abatement schemes for shielded canyons", Appl Acoust, 70, 267-283, (2009)

[4] A. J. Torija and I. H. Flindell, "Listening laboratory study of low height roadside noise barrier performance compared against in-situ field data", Build Environ, 81, 216-225, (2014)

[5] L. Jiang and J. Kang, "Effect of traffic noise on perceived visual impact of motorway traffic", Landsc Urban Plan, 150, 50-59, (2016)

[6] S. Mun and Y. Cho, "Noise barrier optimization using a simulated annealing algorithm", Appl Acoust, 70, 1094-1098, (2009)

[7] T. Van Renterghem and D. Botteldooren, "The importance of roof shape for road traffic noise shielding in the urban environment", J Sound Vib, 329, 1422-1434, (2010)

[8] J. Joynt and J. Kang, "The influence of preconceptions on perceived sound reduction by environmental noise barriers”, Sci Total Environ, 408, 4368-4375, (2010)

[9] D. J. Oldham, C. A. Egan and R. D. Cookson, "Sustainable acoustic absorbers from the biomass", Appl Acoust, 72(6), 350-363, (2011)

[10] T. Van Renterghem and D. Botteldooren, "In-situ measurements of sound propagating over extensive green roofs", Build Environ, 46(3), 729-738, (2011)

[11] H.-S. Yang, J. Kang and C. Cheal, "Random-incidence absorption and scattering coefficients of vegetation”, Acta Acust united Ac, 99(3), 379-388, (2013)

[12] J. Kang, "Sound propagation in street canyons: Comparison between diffusely and geometrically reflecting boundaries", J Acoust Soc Am, 107, 1394-1404, (2000)

Applied Acoustics, Volume 127,2017, Pages 147-159 
[13] J. Kang, "Numerical modelling of the sound fields in urban squares", J Acoust Soc Am, 117, 3695-3706, (2005)

[14] J. Picaut, L. Simon, and J. Hardy, "Sound field modelling in streets with a diffusion equation", J Acoust Soc Am, 106, 2638-2645, (1999)

[15] R. H. Lyon, "Role of multiple reflections and reverberation in urban noise propagation", J Acoust Soc Am, 55, 493-503, (1974)

[16] D. Aylor, J. Y. Parlange, and C. Chapman, "Reverberation in a city street", J Acoust Soc Am, 54, 1754-1757, (1973)

[17] N. W. M. Ko and C. P. Tang, "Reverberation time in a high-rise city", J Sound Vib, 56, 459-461, (1978)

[18] J. Picaut and L. Simon, "A scale model experiment for the study of sound propagation in urban areas", Appl Acoust, 62, 327-340, (2001)

[19] P. Steenackers, H. Myncke, and A. Cops, "Reverberation in town streets", Acta Acust united Ac, 40, 115-119, (1978)

[20] K. W. Yeow, "External reverberation times observed in built-up area", J Sound Vib, 48, 438-440, (1976)

[21] K. W. Yeow, "Decay of sound levels with distance from a steady source observed in a builtup area", J Sound Vib, 52, 151-154, (1977)

[22] M. R. Ismail and D. J. Oldham, “A scale model investigation of sound reflection from building façades”, Appl Acoust, 66, 123-147, (2005)

[23] P. Thomas, T. Van Renterghem, E. De Boeck, L. Dragonetti and D. Botteldooren, "Reverberation-based urban street sound level prediction", J Acoust Soc Am, 133, 3929-3939, (2013)

[24] H. Yang, M. Kim and J. Kang, "Acoustic characteristics of outdoor spaces in an apartment complex", Noise control Eng J, 61(1), 1 10, (2013)

[25] ISO 3382, “Acoustics-Measurement of room acoustic parameters, Part 2: Reverberation time in ordinary rooms", (2008)

[26] IEC 60268-16, "Sound system equipment -Part 16: Objective rating of speech intelligibility by speech transmission index", International Electrotechnical Commission, Geneva, Switzerland, (2003) 